ANL-91/28

Materials and Components

Technology Division Materials and Components Technology Division Materials and Components Technology Division

\section{Practical Superconductor Development for Electrical Power Applications}

Annual Report for FY 1991 
Argonne National Laboratory, with facilities in the states of Illinois and Idaho, is owned by the United States government, and operated by The University of Chicago under the provisions of a contract with the Department of Energy.

\section{DISCLAIMER}

This report was prepared as an account of work sponsored by an agency of the United States Government. Neither the United States Government nor any agency thereof, nor any of their employees, makes any warranty, express or implied, or assumes any legal liability or responsibility for the accuracy, completeness, or usefulness of any information, apparatus, product, or process disclosed, or represents that its use would not infringe privately owned rights. Reference herein to any specific commercial product, process, or service by trade name, trademark, manufacturer, or otherwise, does not necessarily constitute or imply its endorsement, recommendation, or favoring by the United States Government or any agency thereof. The views and opinions of authors expressed herein do not necessarily state or reflect those of the United States Government or any agency thereof.

Reproduced from the best available copy.

Available to DOE and DOE contractors from the

Office of Scientific and Technical Information

P.O. Box 62

Oak Ridge, TN 37831

Prices available from (615) 576-8401, FTS 626-8401

Available to the public from the National Technical Information Service

U.S. Department of Commerce 5285 Port Royal Road

Springfield, VA 22161 
DE92 002839

\author{
ARGONNE NATIONAL LABORATORY \\ 9700 South Cass Avenue \\ Argonne, Illinois 60439
}

\title{
PRACTICAL SUPERCONDUCTOR DEVELOPMENT FOR ELECTRICAL POWER APPLICATIONS \\ ANNUAL REPORT FOR FY 1991
}

Roger B. Poeppel, Coordinator

Kenneth C. Goretta, Compller

\section{Contributors:}

U. Balachandran

I. Bloom ${ }^{\dagger}$

Y. S. Cha

S. E. Dorris

J. T. Dusek

J. E. Emerson

K. C. Goretta
K. E. Gray*
M. C. Hash'
J. R. Hull
J. S. Kallend
R. T. Kampwirth*
M. A. Kirk*
D. S. Kupperman
M. T. Lanagan

V. A. Maronit

R. L. McDaniel

D. J. Miller*

J. J. Picciolo

J. L. Routbort

J. P. Singh

C. A. Youngdahl

Materials and Components Technology Division

October 1991

Work supported by

U.S. DEPARTMENT OF ENERGY

Office of Energy Storage and Distribution

*Materials Science Division.

tChemical Technology Division. 


\section{Contents}

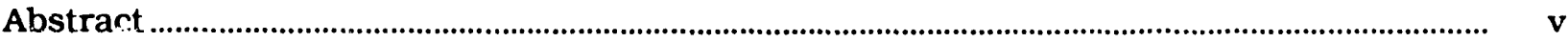

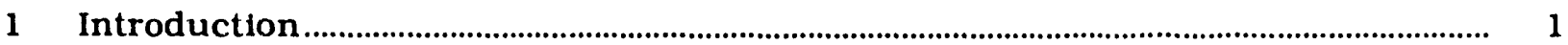

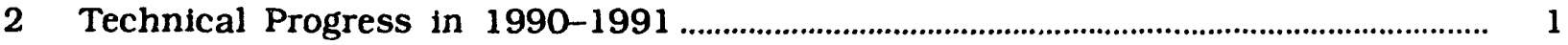

2.1 Synthesis and Heat Treatment .................................................................................... 1

2.1.1 Y-Ba-Cu-O System ................................................................................. 1

2.1.2 Bi-Sr-Ca-Cu-O System .................................................................................. 3

2.1.3 Tl-Ba-Ca-Cu-O System .............................................................................................. 4

2.2 Bulk Conductor Production............................................................................................... 4

2.2.1 Monolithic Conductors ..................................................................................... 4

2.2.2 Composite Conductors.............................................................................................. 7

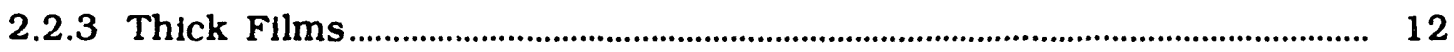

2.3 Properties of Bulk High-T $T_{c}$ Superconductors.................................................... 14

2.3.1 Characterization Methods ............................................................................... 14

2.3.2 Screening Tests ..................................................................................................... 14

2.3.3 Facilities Upgrades and Additions .............................................................. 14

2.3.4 Mechanical Properties....................................................................................... $\quad 15$

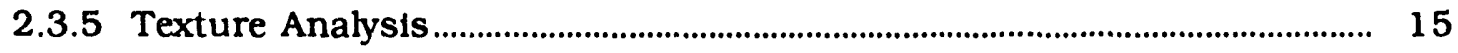

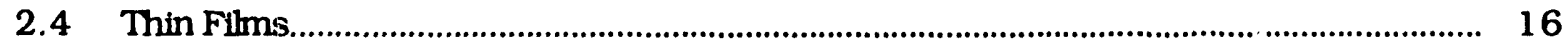

2.4.1 Technical Progress ............................................................................................ 16

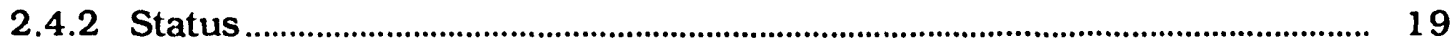

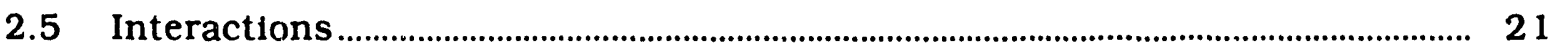

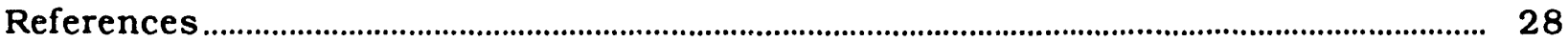




\section{Figures}

1 DTA trace of YBCO reactions from standard precursors and ternary precursors...... 3

2 Optical micrographs of YBCO with nominal Ag contents of $0,0.1,0.06$, and $0.2 \ldots \ldots .9$

3 Dependence of grain size on nominal Ag content ............................................................ 10

4 Variation of analyzed Ag content versus nominal content ................................................. 10

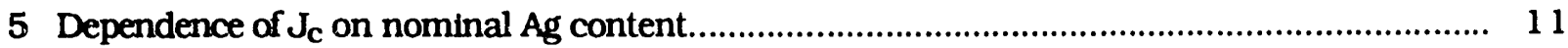

6 TGA traces for various nominal Ag contents .............................................................. 11

7 Data from XRD patterns for YBCO thick films ................................................................ 14

8 Magnetic and transport determinations of $J_{c}$ for an epitaxial film made and patterned by STI into a square and a four-probe layout............................................... 17

9 Irreversibility crossovers for various high-temperature superconductors indicate the approximate regions in $\mathrm{H}$ and $\mathrm{T}$ for current-carrying applications......

10 Results of a proprietary annealing sequence on resistive transitions of bulk $\mathrm{Bi}_{2} \mathrm{Sr}_{2} \mathrm{CaCu}_{2} \mathrm{O}_{x}$ 


\section{PRACTICAL SUPERCONDUCTOR DEVELOPMENT FOR ELECTRICAL POWER APPLICATIONS}

\section{ANNUAL REPORT FOR FY 1991}

\section{Abstract}

Development of useful high-critical-temperature (high- $\mathrm{T}_{\mathrm{c}}$ ) superconductors requires synthesis of superconducting compounds; fabrication of wires, tapes, and films from these compounds; production of composite structures that incorporate stabilizers or insulators: and design and testing of efficient components. This report describes technical progress of research and development efforts aimed at producing superconducting components based on the $\mathrm{Y}-\mathrm{Ba}-\mathrm{Cu}, \mathrm{Bi}-\mathrm{Sr}-\mathrm{Ca}-\mathrm{Cu}, \mathrm{Bi}-\mathrm{Pb}-\mathrm{Sr}-\mathrm{Ca}-\mathrm{Cu}$, and $\mathrm{T}-\mathrm{Ba}-\mathrm{Ca}-\mathrm{Cu}$ oxide systems. Topics discussed are synthesis and heat treatment of high- $T_{c}$ superconductors, formation of monolithic and composite wires and tapes, superconductor/metal connectors, characterization of structures and superconducting and mechanical properties, and fabrication and properties of thin films. Collaborations with industry and academia are also documented. 


\section{Introduction}

The superconductor program at Argonne National Laboratory (ANL) Includes both bulk and film processing development directed toward improving the properties of highcritical-temperature (high- $\mathrm{T}_{\mathrm{c}}$ ) superconductors and developing fabrication methods for production of commercial conductors. Establishment of team relationships with industrial and academic partners is integral to this program. The objective of the ANL program is to develop methods to fabricate and use structurally reliable high- $\mathrm{T}_{\mathrm{c}}$ superconductors for the generation, transmission, and storage of electrical energy. Ceramic processing and joining techniques are being developed to provide useful conductors from one or several of the high- $T_{c}$ superconductors. Work has focused on superconductors based on yttrium-bariumcopper oxide (YBCO), bismuth-strontium-calcium-copper oxide (BSCCO), lead-doped bismuth-strontium-calcium-copper oxide (PBSCCO), and thallium-barium-calcium-copper oxide (TBCCO). Current emphasis is on the Bi-based superconductors.

There are several requirements for monolithic and composite conductors that are formed into wires, tapes, films, and other shapes. The conductors must be capable of carrying large currents in the presence of large magnetic fields and must be strong, flexible, and chemically and cryogenically stable. Potential applications for such conductors include transmission lines, motors, generators, transformers, magnetic energy storage devices, and electronics. The principal impediments to the use of bulk high- $\mathrm{T}_{c}$ superconductors are low critical current density $\left(\mathrm{J}_{\mathrm{c}}\right)$ and poor mechanical properties. Processing methods for the improvement of both have been and continue to be developed. The goals of ceramic fabrication include promoting high conductivity by obtaining phase-pure materials and imparting favorable grain alignment, maximizing flux pinning through microstructural control, and increasing flexibility and reliability by minimizing microstructural flaws and optimizing the toughness of each material.

This report reviews the technical progress and status of (1) synthesis and heat treatment of high- $\mathrm{T}_{\mathrm{c}}$ superconductors; (2) forming of monolithic and composite wires, tapes, and thick films; (3) design and fabrication of superconductor/metal connections; (4) characterization of superconducting and electrical properties, microstructures, and mechanical properties; and (5) fabrication and property evaluations of thin films. Interactions with industry and academia are also documented.

\section{Technical Progress in 1990-1991}

\subsection{Synthesis and Heat Treatment}

\subsection{1 $\mathrm{Y}-\mathrm{Ba}-\mathrm{Cu}-\mathrm{O}$ System}

In the previous period, substantial etfort was concentrated on synthesis of large batches of phase-pure orthorhombic $\mathrm{YBCO}$ powders from $\mathrm{Y}_{2} \mathrm{O}_{3}, \mathrm{BaCO}_{3}$, and $\mathrm{CuO}$ precursors. Reduced-pressure calcination at $\approx 800^{\circ} \mathrm{C}$ was used to prepare tiie superconducting powders. During calcination, $\mathrm{BaCO}_{3}$ decomposes and then reacts to form iniermediate compounds that further react to form the YBCO superconductor. The formation of intermediate compounds during calcination was monitored by X-ray diffraction (XRD), scanning electron microscopy (SEM), and thermal analysis of precursor powders heated to various temperatures up to $800^{\circ} \mathrm{C}$. The reaction passes through the formation of $\mathrm{BaCuO}_{2}, \mathrm{BaCO}_{3}, \mathrm{Y}_{2} \mathrm{Cu}_{2} \mathrm{O}_{5}$. 
and $\mathrm{Y}_{2} \mathrm{BaCuO}_{5}$ (211). The $\mathrm{YBCO}$ phase begins to form at temperatures as low as $725^{\circ} \mathrm{C}$ under an $\mathrm{O}_{2}$ pressure of $2.6 \times 10^{2} \mathrm{~Pa}$. (Balachandran et al., 1991a).

Even though the quality of the superconductor powder produced by reduced-pressure calcination is improved over the conventionally processed material, these powders may still have small amounts of retained carbon. Carbon has an appreciable solubility in YBCO (Lindemer et al., 1990). During synthesis, it is often necessary to hold the powders at temperatures above $950^{\circ} \mathrm{C}$ for long periods to remove the residual carbon. Higher temperatures result in the formation of liquid phases and some nonsuperconducting phases such as 211 and $\mathrm{BaCuO}_{2}$. Use of $\mathrm{BaCuO}_{2}$ (a carbon-free source of $\mathrm{Ba}$ ) in the preparaison of $\mathrm{YBCO}$ will eliminate this problem. From avallable phase-equilibrium information, it is scen that the reaction between $\mathrm{BaCuO}_{2}$ and $\mathrm{Y}_{2} \mathrm{Cu}_{2} \mathrm{O}_{5}$ leads to formation of $\mathrm{YBCO}$ superconductor without any intermediate reaction products. Therefore, we have focused our attention on preparing YBCO by a new method using the ternary precursors $\mathrm{BaCuO}_{2}$ and $\mathrm{CuO}$.

The $\mathrm{BaCuO}_{2}$ is prepared by calcining a mixture of $\mathrm{BaCO}_{3}$ and $\mathrm{CuO}$ at $\approx 850^{\circ} \mathrm{C}$ in flowing $\mathrm{O}_{2}$ at reduced total pressure, followed by ambient-pressure heating at $\approx 925^{\circ} \mathrm{C}$. The $\mathrm{Y}_{2} \mathrm{Cu}_{2} \mathrm{O}_{5}$ is synthesized by a solid-state reaction between $\mathrm{Y}_{2} \mathrm{O}_{3}$ and $\mathrm{CuO}$ in ambient-pressure $\mathrm{O}_{2}$ at $\approx 950^{\circ} \mathrm{C}$. A stoichiometric mixture of $\mathrm{BaCuO}_{2}$ and $\mathrm{Y}_{2} \mathrm{Cu}_{2} \mathrm{O}_{5}$ is heated to $=950^{\circ} \mathrm{C}$ to form $\mathrm{YBCO}$. The reaction between $\mathrm{Y}_{2} \mathrm{Cu}_{2} \mathrm{O}_{5}$ and $\mathrm{BaCuO}_{2}$ is very fast and results in nearly phase-pure YBCO in a short period without the additional formation of intermediate compounds or transient liquids (Balachandran et al., 1991a). Figure 1 shows the differential thermal analysis (DTA) traces during ambient-pressure heating of two precursors: (1) $\mathrm{BaCuO}_{2}$ and $\mathrm{Y}_{2} \mathrm{Cu}_{2} \mathrm{O}_{5}$ mixture; and (2) $\mathrm{Y}_{2} \mathrm{O}_{3}, \mathrm{BaCO}_{3}$, and $\mathrm{CuO}$ mixture. The only observed event in curve (a) is an endotherm, due to peritectic melting of $Y B C O$, with an onset at $\approx 1015^{\circ} \mathrm{C}$. In curve (b), on the other hand, there are three endotherms. The endotherm with onset at $\approx 850^{\circ} \mathrm{C}$ represents the transformation of $\gamma-\mathrm{BaCO}_{3}$ to the tetragonal $\beta$ form (Aselage and Keefer, 1988). The endotherm with onset at $\approx 940^{\circ} \mathrm{C}$ is due to a ternary reaction between YBCO and CuO thai forms 211 and liquid. The endotherm with onset at $\approx 1015^{\circ} \mathrm{C}$ is the result of incongruent melting of YBCO to 211 and a liquid. From Fig. 1, it is apparent that when $\mathrm{Y}_{2} \mathrm{O}_{3}, \mathrm{BaCO}_{3}$, and $\mathrm{CuO}$ mixtures are heated, the result is several intermediate compounds and transient melts in addition to $\mathrm{YBCO}$. However, when $\mathrm{Y}_{2} \mathrm{Cu}_{2} \mathrm{O}_{5}$ and $\mathrm{BaCuO}_{2}$ are used as precursors. YBCO forms with no intermediate compounds or transient melts.

Processing of YBCO superconductors in environments containing $\mathrm{CO}_{2}$ leads to formation of secondary phases such as $\mathrm{BaCO}_{3}, \mathrm{Y}_{2} \mathrm{Cu}_{2} \mathrm{O}_{5}, \mathrm{Y}_{2} \mathrm{BaCuO}_{5}$, and $\mathrm{CuO}$. The kinetics of the gas-solid reaction between $\mathrm{CO}_{2}$ and YBCO superconductors was studied by DTA. thermogravimetric analysis (TGA), dilatometry, XRD, and SEM to examine the decomposition behavior at various partial pressures of $\mathrm{CO}_{2}$ and temperatures. The apparent activation energy of the reaction has been calculated. The decomposition of $\mathrm{YBCO}$ in $\mathrm{CO}_{2}$ atmosphere was found to fit a diffusion-controlled mechanism. Activation energies for chemical diffusion of carbon and oxygen at different partial pressures of $\mathrm{CO}_{2}$ have also been determined.

Decomposition of $\mathrm{YBa}_{2} \mathrm{Cu}_{4} \mathrm{O}_{8}(124)$ into $\mathrm{YBa}_{2} \mathrm{Cu}_{3} \mathrm{O}_{\mathrm{x}}$ has been studied after rapid annealing at temperatures of 800 to $1000^{\circ} \mathrm{C}$. It was found that the superconducting transition temperature depends on the annealing temperature and atmosphere. For decomposed samples, fine-scale defects with strong strain contrasts are observed in the YBCO matrix. High-resolution electron microscopy studies show that the defects are parallel to the (001) planes of the YBCO matrix. The length of the defects varies from 5 to 


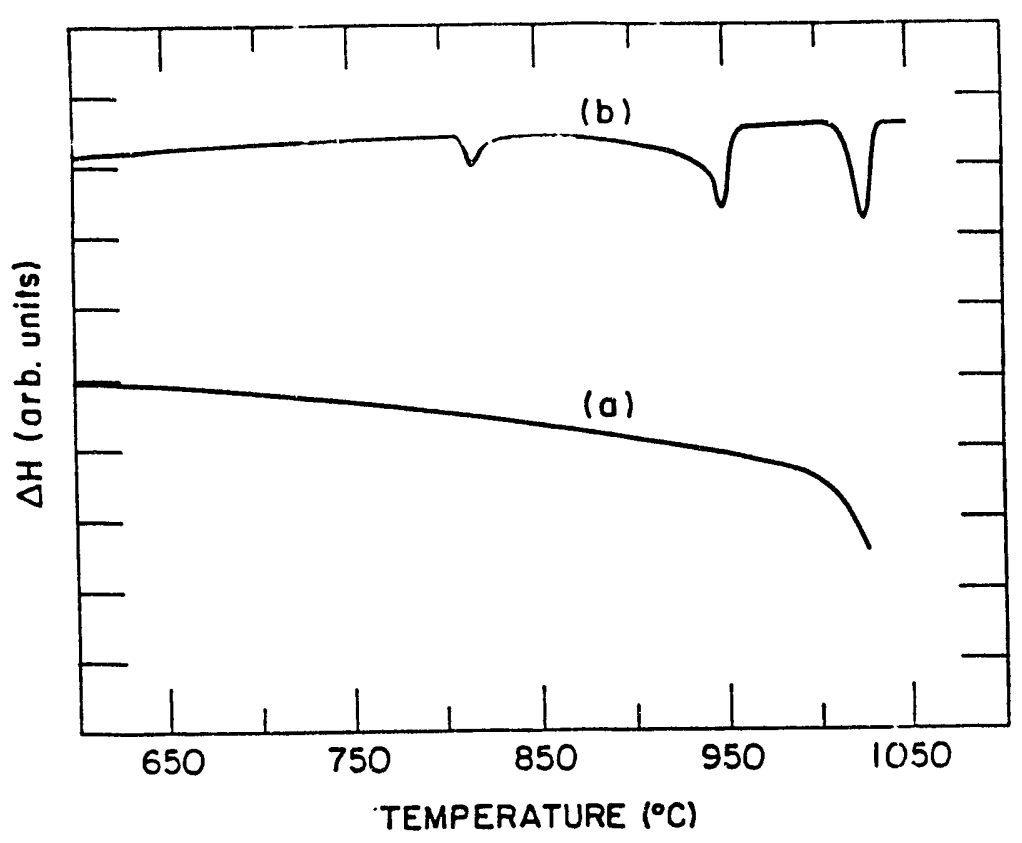

Fig. 1.

DTA trace of YBCO reactions from (a) standard precursors and (b) ternary precursors

$\approx 50 \mathrm{~nm}$ in the direction parallel to the (001) planes. The defects have been interpreted as copper oxides and could be effective flux-pinning centers in these materials (Li et al., 1991).

\subsubsection{Bi-Sr-Ca-Cu-O System}

As reported previously, we now symthesize powder of the $\mathrm{Bi}_{2} \mathrm{Sr}_{2} \mathrm{CaCu}_{2} \mathrm{O}_{\mathbf{x}}$ (2212) phase that is shown to be phase-pure by XRD and DTA. Low-pressure calcination is used to increase reaction kinetics and remove carbon, but higher-pressure $\mathrm{O}_{2}$ is needed to form the desired 2212 phase.

An effort to synthesize phase-pure $2223 \mathrm{BSCCO}\left(\mathrm{T}_{\mathrm{c}} \approx 110 \mathrm{~K}\right)$ is in progress. The kinetics are extremely slow for formation of the 2223 phase, but they can be accelerated significantly by substituting lead for bismuth (Shi et al., 1989a; Dou et al., 1989). Some investigators claim that excess calcium and copper also enhance the kinetics (Shi et al., 1989b; Koyama et al., 1988), but analysis of multiphase samples by electron microprobe has suggested that the 2223 phase is actually alkaline-earth-deficient relative to the ideal composition (Hong and Mason, 1991).

Synthesis at ANL has focused primarily on the composition $\mathrm{Bi}_{1.8} \mathrm{~Pb}_{0.34} \mathrm{Sr}_{2.0} \mathrm{Ca}_{2.2} \mathrm{Cu}_{3.0} \mathrm{O}_{\mathrm{x}}$, and proceeds by solid-state reaction of the constituent oxides and carbonates. The precursor powder mixture is first calcined at $700^{\circ} \mathrm{C}$ under a dynamic vacuum $\left(\approx 2.6 \times 10^{2} \mathrm{~Pa}\right)$ to decompose $\mathrm{SrCO}_{3}$ and $\mathrm{CaCO}_{3}$; it is then calcined in amblent pressure air at $855^{\circ} \mathrm{C}$ for $100 \mathrm{~h}$. The evolution of the X-ray diffraction patterns versus calcination time showed that the amount of 2223 increased up to $100 \mathrm{~h}$, after which no further increase was seen. After $100 \mathrm{~h}$, the materials consist largely of the 2223 phase, together with a small amount of 2212 phase. The zero-resistance $T_{c}$ values of the material have been measured by fourprobe resistivity; they range from 94 to $104 \mathrm{~K}$. 
In a parallel study, slightly different compositions (including $\mathrm{Sb}$ additions) have been used, and again we have adapted our reduced-pressure calcination technique. Nearly phase-pure $\mathrm{Pb}$-doped $\mathrm{BSCCO}$ powders have resulted. In this study, $\mathrm{Bi}_{2} \mathrm{O}_{3}, \mathrm{PbO}, \mathrm{Sb}_{2} \mathrm{O}_{5}$. $\mathrm{SrCO}_{3}$. $\mathrm{CaCO}_{3}$, and $\mathrm{CuO}$ were mixed and heated to $700-750^{\circ} \mathrm{C}$ in flowing $\mathrm{O}_{2}$ at a pressure of $2 \times 10^{2}$ to $1 \times 10^{3} \mathrm{~Pa}$ and held for $\approx 5 \mathrm{~h}$. The vacuum was discontinued, higher-pressure $\mathrm{O}_{2}$ was introduced, the temperature was raised to $\approx 850^{\circ} \mathrm{C}$, and the powder was annealed for $100 \mathrm{~h}$. The synthesized powders were found to be nearly phase-pure, as determined by XRD and RF-SQUID magnetometer.

\subsubsection{TI-Ba-Ca-C $u-O$ System}

Work has commenced recently on fabrication of $\mathrm{TlBa}_{2} \mathrm{Ca}_{2} \mathrm{Cu}_{3} \mathrm{O}_{\mathrm{x}}-\mathrm{Ag}$ clad tapes and wires. This composition has a $T_{c}$ of $\approx 120 \mathrm{~K}$ and has an advantage in that little $T 1$ is evolved during heating (Goretta et al., 1990a). Synthesis of small batches of high-quality powder is required. Two nominal compositions have been used: $\mathrm{TlBa}_{2} \mathrm{Ca}_{2} \mathrm{Cu}_{3} \mathrm{O}_{\mathrm{x}}$ and $\mathrm{TlBa}_{2} \mathrm{Ca}_{2.2} \mathrm{Cu}_{3.3} \mathrm{O}_{\mathrm{x}}$. For both compositions, $\mathrm{Tl}_{2} \mathrm{O}_{3}$ was $\mathrm{n}_{i}$ ixed with calcined $\mathrm{Ba}-\mathrm{Ca}-\mathrm{Cu}$ oxides, placed in a $\mathrm{Pt}$ crucible, and fired in flowing oxygen at $\approx 900^{\circ} \mathrm{C}$. Ag foil was used to seal the crucible. Both powders were shown to be highly phase-pure by XRD and DTA. It seems unlikely that a sufficiently wide range of solid solubility exists for both powders to be a single phase. Work is now focused on synthesizing more powders and examining in closer detail their phase purities.

\subsection{Bulk Conductor Production}

\subsubsection{Monolithic Conductors}

\section{Plastic Wires}

Plastic extrusion is a promising method for producing long lengths of high- $\mathrm{T}_{c}$ superconductors, but requires effective removal of the organic constituents used in extrusion. In the previous report, the benefits of low-pressure firing were described (Poeppel et al.. 1990). The removal of organics is a complicated process involving both heat and mass transfer through a structurally weak body. Incomplete removal leaves residual carbon at grain boundaries, and excessively rapid removal can cause the extruded superconductor to disintegrate. To optimize the removal of organics from large superconductor pieces, the effects of the following were analyzed for the heat treatment of multilayer YBCO coils: total pressure in the furnace, oxygen flow rate, heat conduction, and diffusion of volatile components (Cha et al., 1991).

It was shown previously that firing colls at reduced pressure greatly minimizes or eliminates decomposition of YBCO for two possib!e reasons: (1) $\mathrm{CO}_{2}$ and $\mathrm{H}_{2} \mathrm{O}$ are not allowed to accumulate in the atmosphere because the furnace operates under a dynamic vacuum, and thus the reaction between $\mathrm{YBCO}$ and $\mathrm{CO}_{2}$ and $\mathrm{H}_{2} \mathrm{O}$ is minimized; and (2) the reduced pressure limits the supply of oxygen to the decomposing binder, thereby moderating the binder decomposition reaction and preventing thermal runaway (Dorris et al., 1991). 
Calculation of the velocity and temperature of oxygen at the coll showed that uneven cooling of the coll can result if oxygen is allowed to flow unimpeded into the furnace. This can cause a disparity in the rate at which organics are removed and thus distortion of the coil. Placing a porous material at the entrance to the furnace helps to alleviate this problem by forcing the oxygen to flow along a tortuous path, thereby allowing it to heat before contacting the coil. The porous material also gives a more uniform flow of oxygen through the furnace than does a single small jet of oxygen down the center.

During firing, heat is applied at the coll surface and conducted into its interior. This establishes a temperature gradient, the magnitude of which depends on the heating rate and the size of the coil. Large temperature gradients should be avoided because (1) they induce thermal stresses in a structurally weak body. and (2) they can establish a situation in which part of the coll is undergoing organic removal while another part is not, because decomposition of the organics occurs over a narrow temperature range $\left(\approx 5-10^{\circ} \mathrm{C}\right)$, which also leads to stresses in the weak green body. To understand the effects of heating rate and sample size, the one-dimensional heat-conduction equation was solved for a surface temperature that increases linearly with time.

Heat conduction into the coll interior is controlled by the thermal diffusivity of the organic phase. Because this thermal diffusivity is low $\left(10^{-7}\right.$ to $\left.10^{-8} \mathrm{~m}^{2} / \mathrm{s}\right)$, large steadystate temperature gradients $\left(\approx 50^{\circ} \mathrm{C}\right)$ might be expected across moderately thick coils $(\approx 2 \mathrm{~cm})$ that are heated at $\approx 0.01^{\circ} \mathrm{C} / \mathrm{s}$. This can lead to nonuniform removal of organics from the coil and result in large stresses in the weak green coll. Calculations and experiments show that this problem is avoided when coils are heated at $\approx 0.001^{\circ} \mathrm{C} / \mathrm{s}$.

Finally, the evaporation and diffusion of volatile organics during the early stages of binder removal (below $\approx 200^{\circ} \mathrm{C}$ ) were considered. Evaporation of the volatile organics creates porosity in the green body and thereby facilitates removal of the binder at higher temperatures. If the binder remains in solid form at these low temperatures, migration of the volatile components to the surface proceeds by a slow process of diffusion. If the organics at the interior of the coll volatilize much more rapidly than they diffuse to the surface, bubbles can form and cause bloating of the coll. Solution of the one-dimensional diffusion equation showed that the diffusion of volatile components is much slower than heat conduction, so the entire coll could be above the saturation temperature while most of the volatile components are still trapped in the interior. This could result in bubble formation, but can be prevented by using very slow heating rates.

Careful removal of organics can greatly minimize, if not eliminate, the decomposition of extruded superconductors; however, the level of residual carhon is not clear. This question is important not only for extruded superconductors, but also for any superconductor formed from carbon-bearing precursors, such as carbonates, or exposed to an atmosphere that contains carbon. The role of carbon (in the elemental form or combined with other elements) in high- $\mathrm{T}_{\mathbf{c}}$ ceramic superconductors is recelving increased attention as a possible cause of weak-link behavior. An effort has been initiated to examine the chemical form, quantity, and location of carbon in high- $\mathrm{T}_{\mathbf{c}}$ materials. Both extruded YBCO and BSCCO powder prepared from carbonates are being investigated. 
One aspect of this research involves determinations of total carbon in high- $\mathrm{T}_{\mathbf{c}}$ materials and chemical speciation to establish the various forms of carbon (elemental, carbonate, carbide, hydrocarbon, etc.) that persist in as-synthesized materials. Measurements have been made to quantify the amounts of total carbon and of carbon present as carbonate in YBCO samples prepared by various methods. Work to date has emphasized the use of (1) standard inductively fired combustion methods for total carbon and (2) infrared spectroscopy (using the $\mathrm{KBr}$ pellet technique) for carbonate and hydrocarbons. Total carbon analyses (using a C-LECO Determinator) were performed on YBCO powders prepared from inorganic precursors that included $\mathrm{BaCO}_{3}$ as a source of barium; typical results gave carboncontent values in the range of 0.05 to $0.3 \mathrm{wt} . \%$. From infrared spectroscopic analysis of these same powders. It was found that the quantity of this carbon present as carbonate was below the experimentally determined detection limit of the $\mathrm{KBr}$ pellet technique (i.e.. $0.02 \mathrm{wt} . \%$ carbon as $\left.\mathrm{CO}_{3}{ }^{2-}\right)$. It appears, therefore, that the carbon detected by the C-LECO Determinator is present in a form other than carbonate. Also, when duplicate total carbon analyses were performed on a given YBCO sample, the carbon content values showed a 30 to $40 \%$ variation in most cases and sometimes varied by as much as a factor of 3 . This degree of variability is well beyond the estimated measurement uncertainty of the C-LECO Determinator and indicates that the carbon is distributed nonhomogeneously throughout the YBCO materials.

In related work, a gas phase Fourier transform infrared (FTIR) analysis system has been used to monitor $\mathrm{CO}_{2}$ and hydrocarbon evolution during the firing of extruded YBCO specimens. The temperature domain for primary $\mathrm{CO}_{2}$ evolution occurs between 250 and $400^{\circ} \mathrm{C}$. It is also known that further $\mathrm{CO}_{2}$ evolution occurs at higher temperatures $\left(\approx 800^{\circ} \mathrm{C}\right)$, presumably due to $\mathrm{BaCO}_{3}$ decomposition, but complications associated with the downstream positioning of the infrared detection system from the calcining furnace have made this region of the heat treatment process difficult to monitor. A direct-pyrolysis FTIR technique is being developed that will allow us to take infrared spectra of both the sample and the evolving gases in the immediate vicinity of the sample.

As part of the pyrolysis/FTIR development, diffuse reflectance Fourier transform infrared (DRIFT) spectroscopy has been used to study the evolution and uptake of $\mathrm{CO}_{2}$ by $2223 \mathrm{BSCCO}$ as a function of temperature. When BSCCO that initially contains detectable total carbon $(0.2 \mathrm{wt} \%)$, but not detectable carbonate, is heated to $600^{\circ} \mathrm{C}$ in the DRIFT cell in flowing argon, infrared bands attributable to alkaline earth carbonates appear in the spectrum of the heated material. It is not clear whether this carbonate develops from oxidation of non-carbonate carbon species originally present in the specimen or from traces of $\mathrm{CO}_{2}$ impurity in the sweep gas. In any case, the experiment shows that BSCCO samples originally free of carbonate can pick up $\mathrm{CO}_{2}$ if they are not processed with care. When fully developed, the pyrolysis/FTIR analysis method should shed additional light on the mechanism of $\mathrm{CO}_{2}$ uptake and evolution by $\mathrm{YBCO}$ and $\mathrm{BSCCO}$.

\section{Melted Rods}

Guench-melt-growth processing has been developed to produce YBCO superconductors with a levitation pressure of $\approx 6.8 \times 10^{4} \mathrm{~Pa}$. compared to $\approx 6.8 \times 10^{3} \mathrm{~Pa}$ for the conventionally processed samples. Two of the most important factors used to judge the high- $T_{c}$ materials for magnetic bearing applications are the levitation pressure and the number of rotations per minute that they can achieve. Pressures of $\approx 6-10 \times 10^{4} \mathrm{~Pa}$ are sufficient for the bearing applications. YBCO powders with 211 and $\mathrm{BaSnO}_{3}$ additions were 
heated to $\approx 1450^{\circ} \mathrm{C}$ and held for $2-3 \mathrm{~min}$ and then quenched onto a cold copper plate. Large pellets were pressed from this quenched powder and heated in air to $1050-1100^{\circ} \mathrm{C}$ and held for $\approx 1 \mathrm{~h}$; they were then cooled rapidly $\mathrm{tc} \approx 1020^{\circ} \mathrm{C}$. followed by very slow cooling $\left(1-5^{\circ} \mathrm{C} / \mathrm{h}\right)$ through the peritectic point to $\approx 980^{\circ} \mathrm{C}$. Samples were cooled at a rate of $60^{\circ} \mathrm{C} / \mathrm{h}$ from $980^{\circ} \mathrm{C}$ to $\approx 500^{\circ} \mathrm{C}$ and annealed in oxygen at $\approx 500^{\circ} \mathrm{C}$ for about $24 \mathrm{~h}$ and then cooled to room temperature.

These samples exhibjted good magnetic levitation and flux pinning. Superconducting bearings have been maje in collaboration with the United Technologies Research Center (Weinterger et al.. 1991a).

\subsubsection{Composite Confuctors}

Processing high-temperature superconductors in Ag tubes has produced several reports of $J_{c}$ values of about $10^{4} \mathrm{~A} / \mathrm{cm}^{2}$ at $77 \mathrm{~K}$ and greater than $10^{5} \mathrm{~A} / \mathrm{cm}^{2}$ at $4.2 \mathrm{~K}$. Advantages of powder-in-tube processing include obtaining high green densities, which obviates use of high sintering temperatures; protection of the superconductor from $a^{t}$ mospheric exposure; and possible stabilization of the superconductor by the metallic sheath. $\mathrm{Ag}$ is used as the sheath because of $1 \mathrm{ts}$ compatibility with the high- $\mathrm{T}_{\mathrm{c}}$ superconductors.

Wiies and Tapes

At ANL, research has included swaging, drawing, pressing, and rolling operations (C.-T. Wu et al., 1991). Results to date indicate that the $J_{c}$ for sintered YBCO forms is unlikely to e rceed $\approx 10^{4} \mathrm{~A} / \mathrm{cm}^{2}$ at $77 \mathrm{~K}$ and drops rapidly with applied field. The microstructures for . BCO developed to date have been only modesily textured, and in the absence of melting. little improvement in texture is expected.

We have fabricated Ag-clad BSCCO wires with i.luch higher degrees of texture. At $77 \mathrm{~K}$. contact heating problems are common, and zero-field $J_{c}$ values are $\approx 10^{3} \mathrm{~A} / \mathrm{cm}^{2}$. The $J_{c}$ decreases about $30 \%$ in an applied field of $2.5 \mathrm{mT}$. Measurements at $4.2 \mathrm{~K}$ indicated that $\mathrm{J}_{\mathrm{C}}$ reaches $\approx 4 \times 10^{3} \mathrm{~A} / \mathrm{cm}^{2}$. No drop in $\mathrm{J}_{\mathrm{c}}$ is observed for fields up to $2.5 \mathrm{mT}$. Measurements are now being made at $35 \mathrm{~K}$.

Specimens can only be measured once or twice because of thermal stresses experienced during cooling. Effects of thermal shock are now under investigation.

Ag-clad $\mathrm{TlBa}_{2} \mathrm{Ca}_{2} \mathrm{Cu}_{3} \mathrm{O}_{\mathrm{x}}$ (TBCCO 1223) wires and tapes have been fabricated. The wires can carry about $10 \mathrm{~A}$ at $77 \mathrm{~K}$ and 30-40 A at 4.2 K. The highest Jc values have been $2 \times 10^{3}$ $\mathrm{A} / \mathrm{cm}^{2}$ at $77 \mathrm{~K}$ and $=10^{4} \mathrm{~A} / \mathrm{cm}^{2}$ at $4.2 \mathrm{~K}$. The response to a magnetic fieid has been similar to that of a BSCCO superconductor. At this point, the Ag- lad TBCCO tapes appear to have a weak-link problem. Solid-state sintering has not been able to remove the weak links. Various partial-melting heat treatments are now being used.

\section{Effects of $\mathrm{Ag}$}

Substitution of $\mathrm{Ag}$ for $\mathrm{Cu}$ sites has been used to increase the $\mathrm{T}_{\mathrm{c}}$ of YBCO superconductors (Matsumoto et al., 1988; Shao et al. 1988). However, the nature of the Ag substitution on the $\mathrm{Cu}$ sites is not comr:utely understood. Therefore, an effort to evaluate the nature of Af solubility in YECO and the effects of Af doping on the micostructure and 
properties of YBCO has been initiated. To this end, the $\mathrm{Ag}$-doped $\mathrm{YBa}_{2} \mathrm{Cu}_{3-\mathrm{x}} \mathrm{Ag}_{\mathrm{x}} \mathrm{O}_{\mathrm{y}}$ powder was made by solid-s'tate reaction of the constituent powders $\mathrm{Y}_{2} \mathrm{O}_{3}, \mathrm{BaO}, \mathrm{CuO}$, and Ag. To achieve this doping, the amount of $\mathrm{Ag}$ addition was varied from a nominal value of $\mathrm{x}=0$ to 0.5. The powders were pressed into disk-shaped pellets with a diameter of $1.27 \mathrm{~cm}$ and a thickness of $=0.25 \mathrm{~cm}$. These pellets were sintered at $940^{\circ} \mathrm{C}$ for $10 \mathrm{~h}$ in flowing $\mathrm{O}_{2}$. followed by a $12-\mathrm{h}$ anneal at $450^{\circ} \mathrm{C}$.

Figures 2 and 3 show optical micrographs of the Ag-doped YBCO specimens and the dependence of grain size on nominal Ag content, respectively. Initially, the grain size of the $\mathrm{Ag}$-doped YBCO specimens remains nearly constant $(=18 \mu \mathrm{m})$ at very low nominal $\mathrm{Ag}$ contents of $x \leq 0.01$. With further increases in Ag content $(x>0.01)$, the grain size begins to decrease. A value of $\approx 2.5 \mu \mathrm{m}$ is achieved at an Ag content of $\approx 0.1$. For Ag contents greater than $x>0.1$, the grain size remains approximately constant at a value of $\approx 2 \mu \mathrm{m}$. This dependence of YBCO grain size on Ag content is believed to be related to the precipitation of Ag on YBCO grain boundaries. As indicated by secondary and backscatter electron micrographs, a limited amount of Ag has precipitated at YBCO grain boundaries even at low Ag contents $(x=0.06)$. The precipitated Ag particles pin the YBCO grains and hence suppress the grain growth. The amount of Ag precipitates ircreases and hence the grain size decreases with increasing nominal Ag content. For higher Ag contents $(x \geq 0.01)$, the average grain size is on the order of average starting particle size and thus does not decrease further.

$\mathrm{X}$-ray diffraction analysis indicates that YBCO specimens (with and without Ag doping) have orthorhombic superconductor structure. For Ag contents less than 0.01, these specimens appear as a single phase of YBCO and do not show the presence of the Ag phase. For the sample: with Ag contents greater than 0.01, the XRD patterns indicate the presence of $\mathrm{Ag} F$ ise, along with nonsuperconducting phases such as $\mathrm{Y}_{2} \mathrm{BaCuO}_{5}, \mathrm{BaCuO}_{2}$. and $\mathrm{Y}_{2} \mathrm{Cu}_{2} \mathrm{O}_{5}$. The concentrations of these nonsuperconducting second phases increase with increasing Ag contents.

Figure 4 shows the variation in Ag contents $(x)$ in YBCO structure as obtained by quantitative wavelength dispersive electron probe microanalysis (EPMA) with the nominal Ag content $\left(x_{n}\right)$. The analyzed Ag content increases approximately linearly with $x_{n}$ in the range of $0<x_{n} \leq 0.1$. However, the slope of this line is less than 1, suggesting that all of the Ag added to YBCO during fabrication does not go onto the $\mathrm{Cu}$ lattice sites. This is consistent with both the microstructural observations and $\mathrm{X}$-ray diffraction results that indicate the presence of Ag precipitation in YBCO even at low nominal Ag contents ( $x_{n}<$ 0.06). The fact that all of the $\mathrm{Ag}$ does not go onto $\mathrm{Cu}$ lattice sites and partially precipitates at the YBCO grain boundaries, even for low nominal Ag contents, is believed to be related to processing problems. A better mixing of Ag with YBCO is expected to eliminate or minimize Ag precipitation. For higher Ag contents $\left(x_{n}>0.1\right)$, the amount of $\mathrm{Ag}$ in the YBCO structure, as analyzed by EPMA, remains approximately constant at $x=0.06$. This suggests that the solubility limit of $\mathrm{Ag}$ for $\mathrm{Cu}$ sites in YBCO is 0.06 .

The measured values of $J_{c}$ at $77 \mathrm{~K}$ are shown in Fig. 5. $J_{c}$ increases from 100 to 160 $\mathrm{A} / \mathrm{cm}^{2}$ as Ag content increases from $x_{n}=0$ to $x_{n}=0.2$. Further increase in Ag contents results in a corresponding decrease in $J_{c}$. Although the absolute magnitude of $J_{c}$ is not large, the variation in $J_{c}$ (the increase for low Ag contents and subsequent decrease for high Ag contents) is significant for the fabrication of Ag-doped YBCO superconductors. Figure 6 shows TGA traces for YBCO (with and without Ag doping) in a flowing oxygen atmosphere 

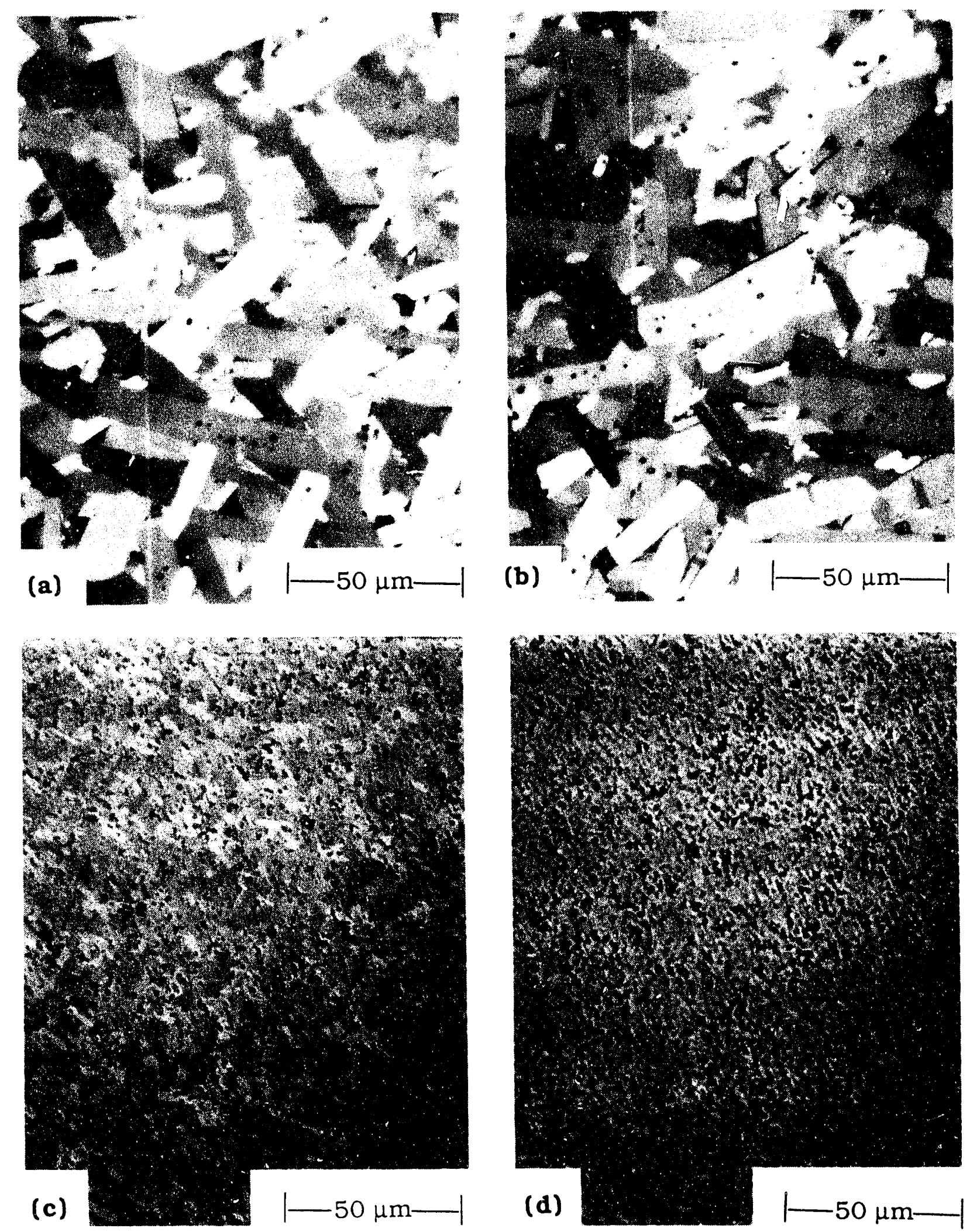

Fig. 2. Optical micrographs of YBCO with nominal Ag contents of (a) 0 , (b) 0.01 , (c) 0.06 , and (d) 0.2 


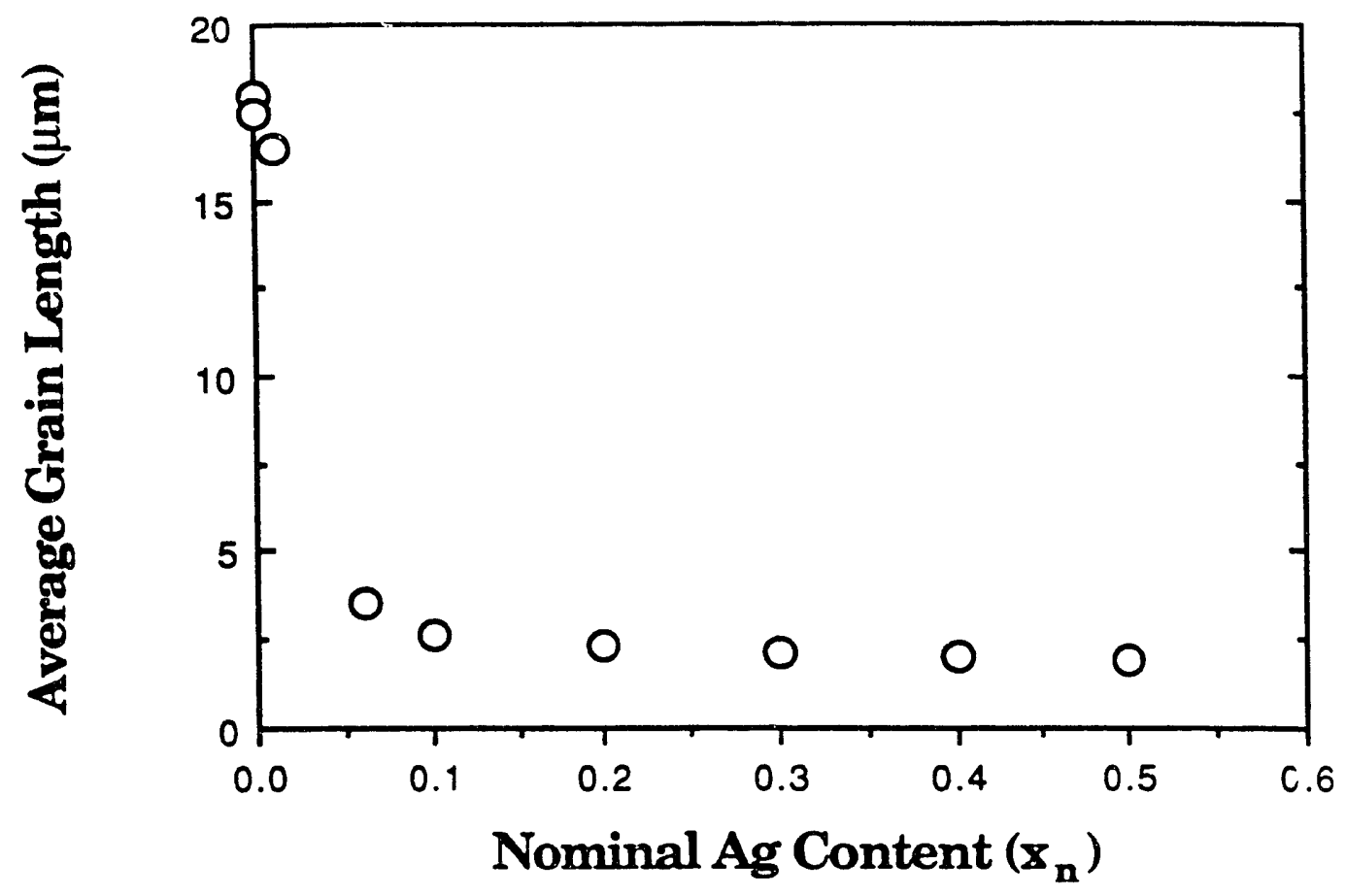

Fig. 3. Dependence of grain size on nominal Ag content

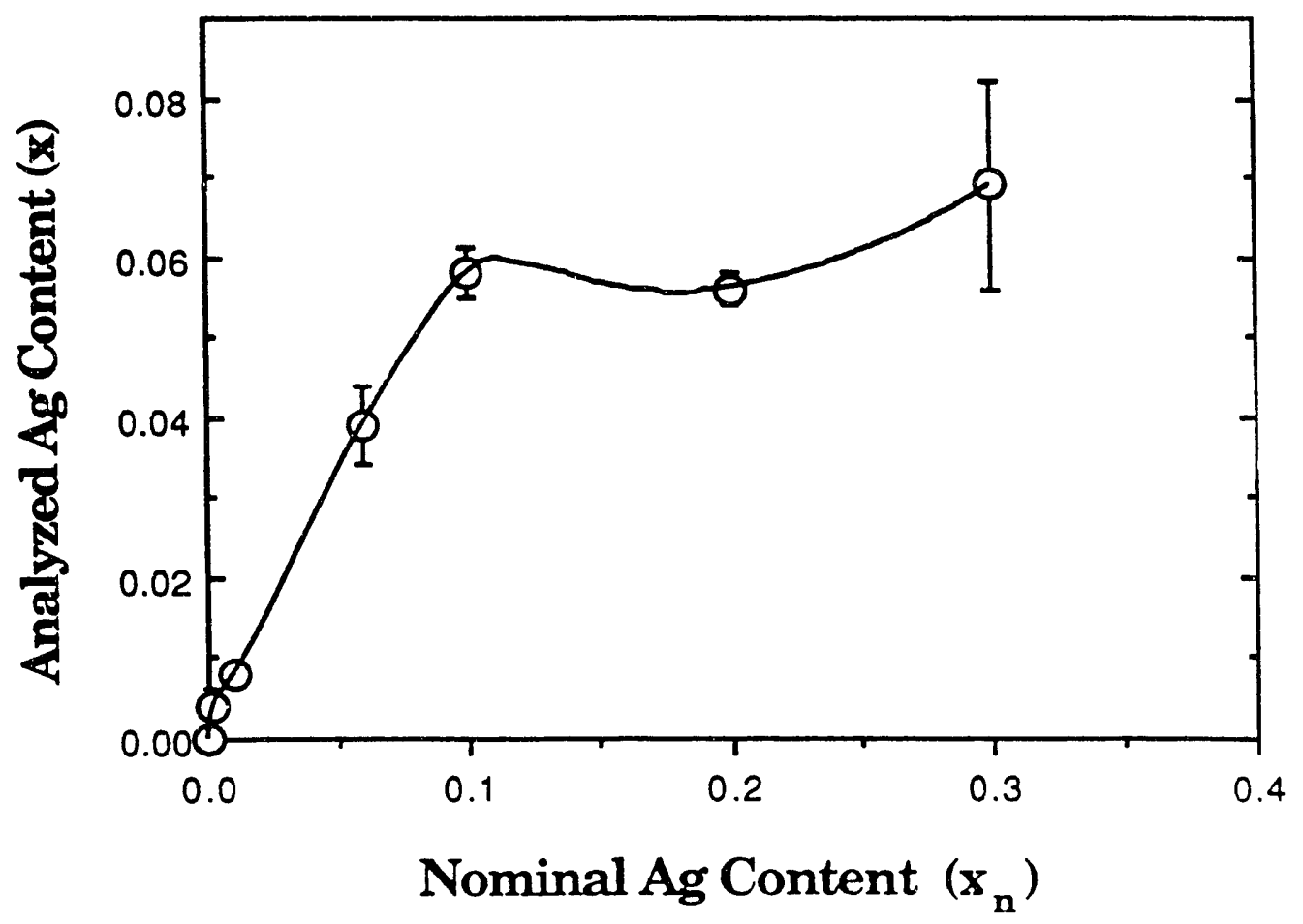

Fig. 4. Varlation of analyzed Ag content versus nominal content 


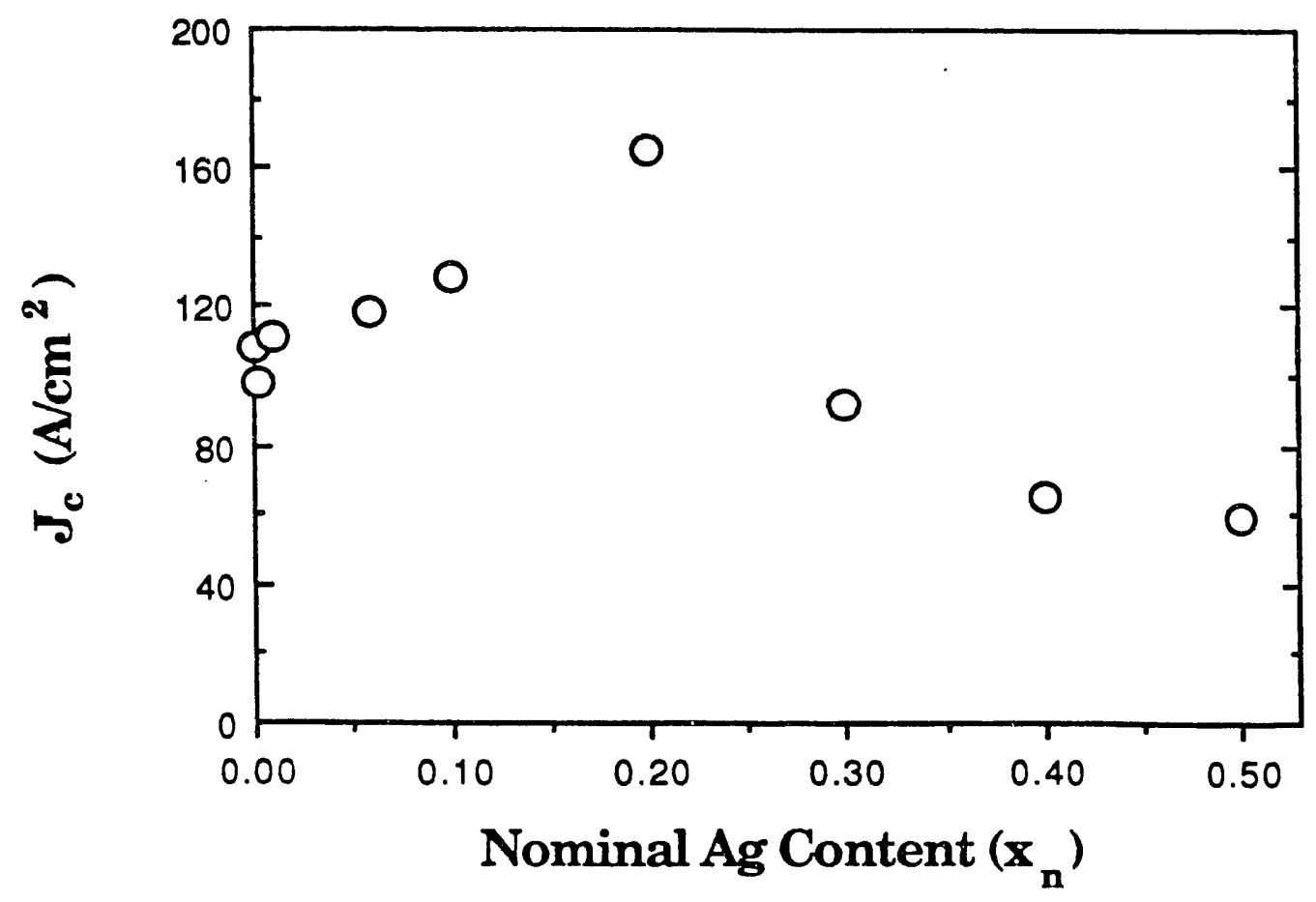

Fig. 5. Dependence of $J_{c}$ on nominal Ag content

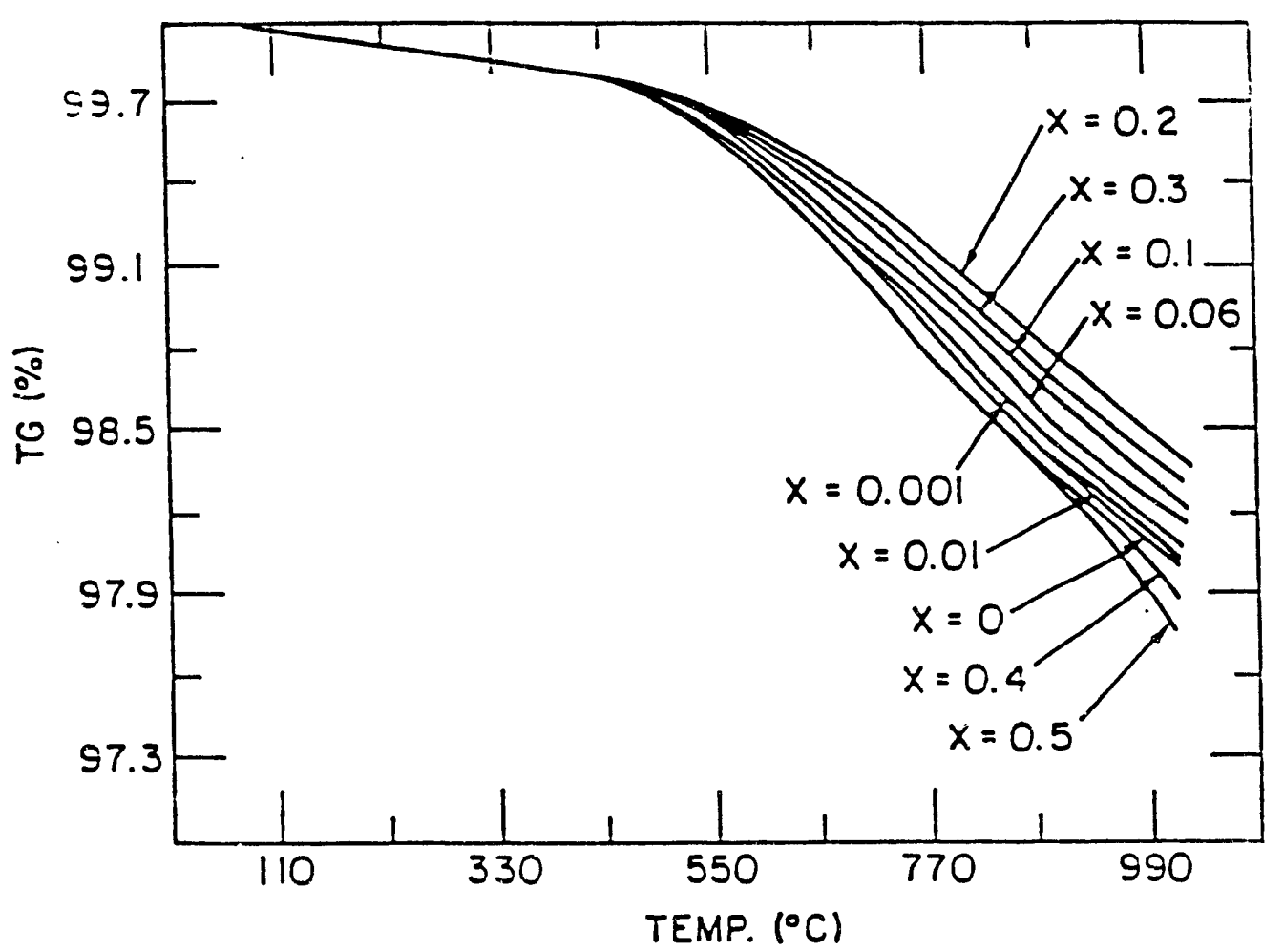

Fig. 6. TGA traces for various nominal Ag contents 
with a heating rate of $3^{\circ} \mathrm{C} / \mathrm{min}$. It can be seen that these YBCO specimens lose mass above $500^{\circ} \mathrm{C}$. Furthermore, the mass loss decreases with increasing Ag contents for $0<x_{n} \leq 0.2$ and increases with increasing Ag contents for $x_{n} \geq 0.2$. This mass loss is believed to be the result of axygen removal from the one-dimensional $\mathrm{Cu}-\mathrm{O}$ shains (Cahen et al., 1987; Simmins and Snyder, 1988).

Therefore, a plausible explanation for the decrease in weight loss upon heating for low Ag contents $\left(0<x_{n} \leq 0.2\right)$ may be the strengthening and stabilization of the onedimensional oxygen chains because of the presence of Ag. Stabilization of the oxygen content of YBCO may help to improve $\mathrm{J}_{\mathrm{c}}$. This is consistent with the observed increase in $\mathrm{J}_{\mathrm{c}}$ for Ag contents $\left(0<\mathrm{x}_{\mathbf{n}} \leq 0.2\right)$, as shown in Fig. 5. However, at higher Ag contents $\left(x_{n} \geq 0.2\right)$ the solubility limit of Ag is exceeded. This will enhance the formation of nonsuperconducting second phases such as $\mathrm{Y}_{2} \mathrm{BaCuO}_{5}, \mathrm{BaCuO}_{2}$, and $\mathrm{Y}_{2} \mathrm{Cu}_{2} \mathrm{O}_{5}$ and thus degrade $J_{c}$.

\subsubsection{Thick Films}

\section{Powder-Derived Films}

As reported previously, novel microstructures can be produced by melt-solidification processing of BSCCO thick films. Crystal growth kinetics are highly anisotropic, and the fastest growth is in the $a-b$ plane. As a result, platelike grains with large aspect ratios are commonly observed in microstructures of high- $T_{c}$ materials. The kinetics of heterogeneous nucleation and growth favor propagation of the $a-b$ directions along the substrate plane. Highly textured microstructures have been developed for BSCCO thick films by this process.

Thick films of 2212 BSCCO were fabricated by applying a highly viscous slurry composed of a superconducting powder and an organic solvent. A dispersant was used to deflocculate particles and enhance rheological properties. The slurries were painted on Ag. $\mathrm{Au}$, or MgO substrates and dried at $60^{\circ} \mathrm{C}$ for $4 \mathrm{~h}$. The specimens were subsequently fired at high temperature and characterized by SEM, XRD, and DC current transport. The major phase for the 2212 composition was $\mathrm{Bi}_{2} \mathrm{Sr}_{2} \mathrm{CaCu}_{2} \mathrm{O}_{\mathbf{X}}$. Several low-intensity diffraction peaks appeared, but could not be identified as the 2212 compound. The microstructure consisted of large, long, highly oriented crystals. The c-axis of the crystal lattice was found to be perpendicular to the piane of the thick film. Transport $J_{c}$ values have been difficult to obtain because of problems with contact heating at the current leads. Measurement to date indicate that the best $J_{c}$ values at $4.2 \mathrm{~K}$ are at least $\approx 10^{4} \mathrm{~A} / \mathrm{cm}^{2}$. Additional work is in progress.

\section{Sol-Gel Films}

YBCO superconducting films on polycrystalline Ag substrates have been fabricated by a sol-gel/spray-pyrolysis method. X-ray diffraction analysis confirms that these films are highly textured; however, grain alignment is virtually lost for films thicker than $3 \mu \mathrm{m}$. Sol-gel processing is an efficient technique for preparing thick films of YBCO. The process is relatively simple and is well suited to coating complex shapes. Vapor deposition techniques, for example, require long times to build up a sufficiently thick films and have more difficulty in uniformly coating complex shapes. 
Substrate selection for thick films is based on several criteria. Sol-gel deposition on dielectric substrates has been explored for microelectronic applications. Highly oriented films have been deposited on $\mathrm{MgO}$ and $\mathrm{SrTiO}_{3}$ substrates (Hirano et al., 1990), and textured sol-gel films have also been obtained on zirconia substrates (Shibata et al., 1988). For several applications, such as motors and high-power cavities, the high-temperature superconductors must be bonded to a normal conductor. If the superconductor should quench. the current will shunt across the normal conductor. The generated thermal energy can also be removed from the superconductor via the metal substrate to prevent quenching.

Coprocessing of materials will entail studies of interfaces between superconductor and substrate materials. A strong bond will usually result when there is a small amount of interdiffusion, although excessive diffusion of the substrate material into the supercciductor may result in property degradation. Silver is an excellent choice for a substrate because of its relatively high thermal expansion coefficient and chemical compatibility with superconductors (Singh et al., 1989; Lanagan et al., 1990).

The sol-gel process for growth of YBCO oxide films has been discussed in detail (Poeppel et al., 1990). For this work, the thick films were deposited onto Ag substrates. Reagent-grade metal acetates were obtained from commercial sources (Aldrich and Baker) and analyzed to determine their levels of hydrated water. Analyses showed the starting metal acetate formulas to be $\mathrm{Y}\left(\mathrm{CH}_{3} \mathrm{COO}\right)_{3} \cdot 3 \mathrm{H}_{2} \mathrm{O}, \mathrm{Cu}\left(\mathrm{CH}_{3} \mathrm{COO}\right)_{2} \cdot 0.8 \mathrm{H}_{2} \mathrm{O}$, and $\mathrm{Ba}\left(\mathrm{CH}_{3} \mathrm{COO}\right)_{2}$. The YBCO precursor solution was prepared from the metal acetate salts dissolved in distilled water. A typical procedure involved mixing appropriate amounts of yttrium acetate trihydrate, barium acetate, and copper acetate monohydrate in $89.5 \mathrm{~mole} \%$ of distilled water. The solution was heated to $60^{\circ} \mathrm{C}$ and stirred to dissolve the solids. Monoethanolamine $(8.4 \mathrm{~mole} \%)$ was then added slowly while stirring.

Spray-coating of the substrates at $300^{\circ} \mathrm{C}$ appeared to produce the best coatings. The substrates were heated with a hot plate in ambient air. A small hand-held spray gun was used for preparing films. The best films were produced by spray-coating polycrystalline Ag heated to $300^{\circ} \mathrm{C}$, followed by a $550^{\circ} \mathrm{C}$ treatment. Film thickness could be adjusted by repeating this procedure. Typically, Ag was coated five times, resulting in a final YBCO film thickness of $1-3 \mu \mathrm{m}$. The final sintering was accomplished at $900^{\circ} \mathrm{C}$ for $8 \mathrm{~h}$ in flowing $1 \%$ $\mathrm{O}_{2}$ in $\mathrm{N}_{2}$, followed by an $\mathrm{O}_{2}$ anneal upon cooling.

Sample arrays of eight specimens, each with a thickness between 1 and $10 \mu \mathrm{m}$, were heat treated at 870,900 , and $930^{\circ} \mathrm{C}$. Films sintered at $870^{\circ} \mathrm{C}$ were composed of small grains, and no impurity phases were detected by XRD or SEM. At 900 and $930^{\circ} \mathrm{C}$. significant grain growth occurred. Qualitative texture studies were carried out by XRD and suggested that grain alignment occurred in films less than $4 \mu \mathrm{m}$ thick (Fig. 7). The intensity ratio $(005) /(110)$ was about 0.01 for a randomly oriented powder, and the enhanced $100 \hat{u}$ diffraction intensities indicated that the c-axis was perpendicular to the substrate plane. Films sintered at $900^{\circ} \mathrm{C}$ were highly oriented with (005)/(110) peak height ratios approaching a value of 10 . Microstructural analysis on films heat treated at $930^{\circ} \mathrm{C}$ revealed that a reaction occurred at the $\mathrm{Ag} / \mathrm{YBCO}$ interface. Extensive amounts of $\mathrm{Y}_{2} \mathrm{BaCuO}_{5}$ and $\mathrm{YBa}_{4} \mathrm{Cu}_{3} \mathrm{O}_{\mathrm{x}}$ were dispersed among the $\mathrm{YBa}_{2} \mathrm{Cu}_{3} \mathrm{O}_{\mathrm{x}}$ grains. 


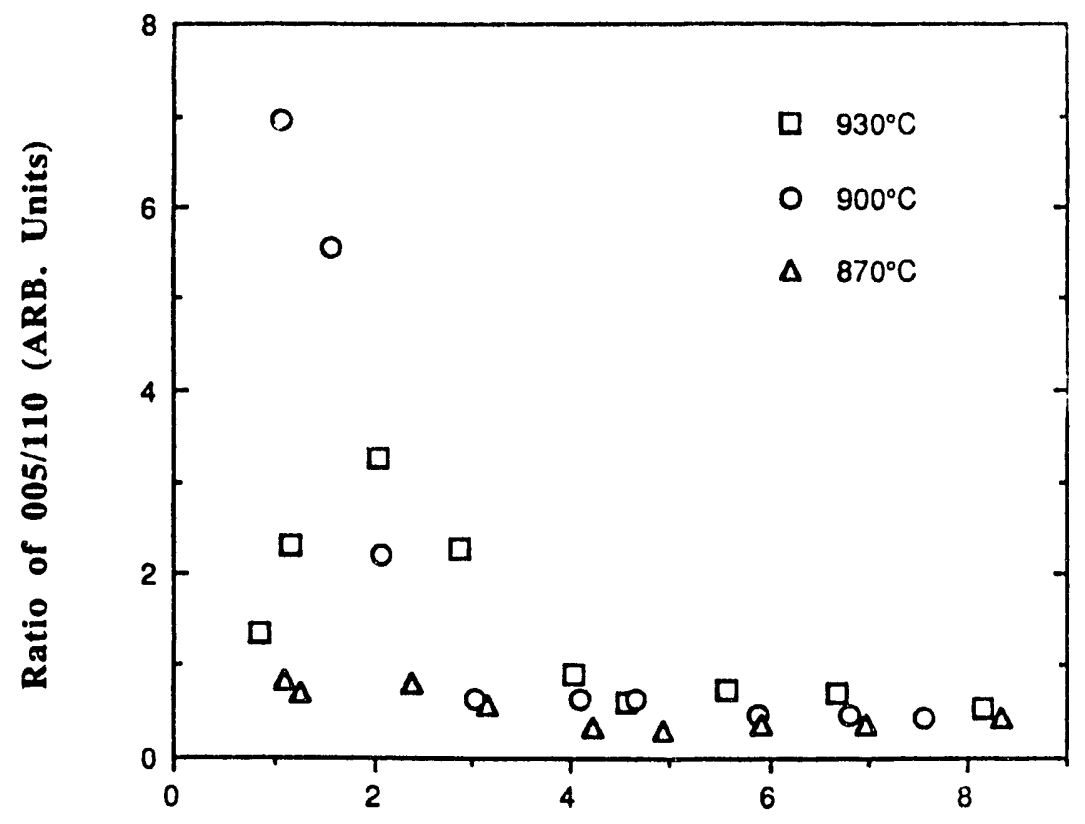

Thickness $(\mu \mathrm{m})$

Fig. 7. Data from XRD patterns for YBCO thick films

\subsection{Properties of Bulk High-Tc Superconductors}

\subsubsection{Characterization Methods}

Ceramic superconductor samples produced by ANL are characterized to help guide improvement of the chemical formulations and the forming and processing procedures. High- $\mathrm{T}_{c}$ products fabricated by ANL for use by others also are characterized to evaluate product performance. The property of primary interest is the DC transport critical current value $\left(I_{c}\right)$ of the sample or the critical current density $\left(J_{c}\right)$. measured as a function of the intensity of an applied magnetic field. Selected samples are tested to find the critical temperature, AC resistance. structural defects, or strength of the diamagnetic response, remanent field strength, and magnetic shielding performance.

\subsubsection{Screening Tests}

$J_{c}$ tests have continued at an average rate of $\approx 40$ new samples each month. Substantial differences among batches of bulk material or formed products necessitated continual screening. The standarci four-point resistance method was used with a $1-\mu \mathrm{V} / \mathrm{cm} \mathrm{J}_{\mathrm{c}}$ criterion.

\subsubsection{Facilities Upgrades and Additions}

A 200-A pulsed-current system for measurement of transport $J_{c}$ wרs assembled. The design of the sample-support probe segregates and shields the voltage-monitoring leads from the current leads and locates the measurement ground connection near or on the samples. With this arrangement, the common mode signal is negligible. In addition, the 
effective level of ambient electrical noise is reduced to less than $1-\mu \mathrm{V}$ input equivalent when the probe is used with low-pass filtering consistent with the application of current pulses $100 \mathrm{~ms}$ or greater in duration. A signal-averaging capability is provided for use with shorter pulses.

The pulser was used to test powder-in-tube and melt-textured superconductors with high critical currents at 4.2 and $35 \mathrm{~K}$. The measured values are given elsewhere in this report.

\subsubsection{Mechanical Properties}

Mechanical-property research has continued. The fracture toughness $\left(\mathrm{K}_{\mathrm{IC}}\right)$ and strength of most high- $\mathrm{T}_{\mathrm{c}}$ superconductors are poor. Previous efforts led to improvements for $\mathrm{YBCO}$ in $\mathrm{K}_{\mathrm{IC}}$ from $\approx 1.5 \mathrm{MPa} \sqrt{\mathrm{m}}$ to $4.5 \mathrm{MPa} \sqrt{\mathrm{m}}$ and strength from $\approx 100 \mathrm{MPa}$ to $\approx 200 \mathrm{MPa}$ (Poeppel et al., 1990). $\mathrm{K}_{\mathrm{IC}}$ was increased by additions of particulate Ag and 211-coated $\mathrm{ZrO}_{2}$. Strength was increased by low-pressure sintering methods designed to minimize grain growth while maximizing density.

Current efforts are now focused on the properties of BSCCO superconductors. Sintering studies are examining the effects of Ag additions on microstructural development. Hot isostatic pressing has been used to make dense 2212 BSCCO bulk specimens (Nash et al., 1990). These specimens are being used for preliminary mechanical-property studies. BSCCO superconductors are too soft to permit indentation testing of $\mathrm{K}_{\mathrm{fC}}$. Larger bars are now being pressed so that notched specimens can be used for $\mathrm{K}_{\mathrm{IC}}$ and strength determinations.

High-temperature mechanical-deformation studies continue for both YBCO and BSCCO. For YBCO, current efforts are focused on measuring steady-state creep of samples doped with $\mathrm{Zr}$, Dy, and $\mathrm{Ca}$. To date, however, the creep rate appears to be nearly independent of doping. The experiments will conclude shortly, and a definitive answer to the effects of doping will be obtained after the effects of phase purity and grain size have been fully accounted for (creep rates are approximately proportional to grain size to the -2.8 power (Goretta et al., 1990b)).

Creep testing of 2212 BSCCO has begun in an effort to obtain diffusional information. When compressed at 825 to $850^{\circ} \mathrm{C}$ under stresses equal to those used in creep testing of YBCO, the individual platelike grains of 2212 bend. Therefore, no diffusional creep has been measured. We are now preparing larger specimens for testing at much lower loads. These tests are important because to date no diffusional properties have been reported for BSCCO superconductors.

\subsubsection{Texture Analysis}

The previous report detalled development of the ability to measure quantitatively preferred orientations in high- $\mathrm{T}_{\mathbf{c}}$ superconductors through use of an orientation distribution function (ODF). Results obtained by XRD for a 2212 BSCCO thick film were discussed earlier (Poeppel et al., 1990). In the past year, XRD has been used to quantify the textures of sinter-forged YBCO and BSCCO (Blondo et al., 1991), melt-textured YBCO, and $2212 \mathrm{BSCCO} / \mathrm{Ag}$ tapes. Neutron diffraction has been used to quantify textures of sinterforged YBCO (Biondo et al., 1990) and melt-textured YBCO. Efforts at modeling the effects 
of texture on $J_{c}$ have progressed on two fronts. From the experimental standpoint, we now make two strongly linked types of superconductors, melt-textured YBCO and powder-intube BSCCO, that circumvent problems assoclated with grain boundary weak links. From the theoretical standpoint, we developed a new computer code that can take an ODF and generate a misorientation distribution function; this function gives the likelihood of finding adjacent grains with given orientations. Such information can be coupled with percolation theory and boundary-value $J_{c}$ criteria to provide a model of the relationship between $J_{c}$ and texture. Work continues on this difficult problem.

\subsection{Thin Films}

Practical high- $T_{c}$ superconductors must reliably carry high current densities in a flexible conductor: thin films have demonstrated this potential. The purpose of this task is to explore the low-temperature, nonepitaxial growth of high- $T_{c}$ thin films on practical substrates in a manner compatible with continuous fabrication of long wires and tapes. The high formation temperature needed for $h i g h-T_{c}$ supercoriductors can lead to substrate interdiffusion and loss of the highly volatile species. This program specifically addresses novel processing of high- $T_{c}$ films in a single-step, low-temperature sputter deposition. Optical in-situ analyses, which are compatible with all forms of vapor deposition, are used to efficiently evaluate such processes. This study concentrates on the B1- and T1-based cuprate high- $\mathrm{T}_{c}$ films because they achieve good superconducting properties without the need for single-crystal, epitaxial substrates. Ex-situ analyses include SEM and transmission electron microscopy (TEM). Finally, this study specifically addiresses deposition onto practical substrates and continuous processing of wires and tapes in one of many collaborations.

\subsubsection{Technical Progress}

The superconducting properties of epitaxial films of $\mathrm{Tl}_{2} \mathrm{Ba}_{2} \mathrm{CaCu}_{2} \mathrm{O}_{\mathrm{x}}$, supplied by Superconductor Technologies. Inc. (STI) of Santa Barbara, CA, have been measured and compared with polycrystalline, highly oriented films made at ANL. The broadened resistive transitions in a magnetic field near $T_{c}$ are essentially identical, but $J_{c}$ for the epitaxial films was one order of magnitude higher at lower $\mathrm{T}$ and $\mathrm{H}$ values. Both magnetic and transport determinations of $J_{c}$ are shown in Fig. 8 for another epitaxial film, which was patterned by STI into a square (for magnetic $J_{c}$ ) and into a four-probe layout for transport.

We also measured the effect of anisotropy on the field-induced broadening of resistive transitions in the most highly anisotropic superconductor, using samples made at STI. Westinghouse, Northwestern University, and ANL. For $\mathrm{H}$ parallel to the superconducting Cu-O layers. the absence of a Lorentz force and the intrinsic pinnirig of the insulating region between layers imply that a residual dissipation other than flux motion is observed. However, for $\mathrm{H}$ parallel to the $c$-axis, the lack of intrinsic pinning implies that the much greater broadening is due to thermally activated flux motion. Our experiments show that this flux motion occurs as a result of a crossover from three-dimensional (3-D) vortex lines to 2-D independent pancakelike vortices, which reside in the $\mathrm{Cu}-\mathrm{O}$ layers. This 3-D-to-2$\mathrm{D}$ crossover occurs when $\mathrm{k}_{B} \mathrm{~T}$ exceeds the interlayer Josephson coupling energy. For the less anisotropic $\mathrm{YBa}_{2} \mathrm{CL}_{3} \mathrm{O}_{\mathrm{x}}$, this dimensional crossover does not occur below the upper critical field $\left(\mathrm{H}_{\mathrm{c} 2}\right)$, presı imably because the conducting $\mathrm{Cu}-\mathrm{O}$ chains short-circuit the weak 


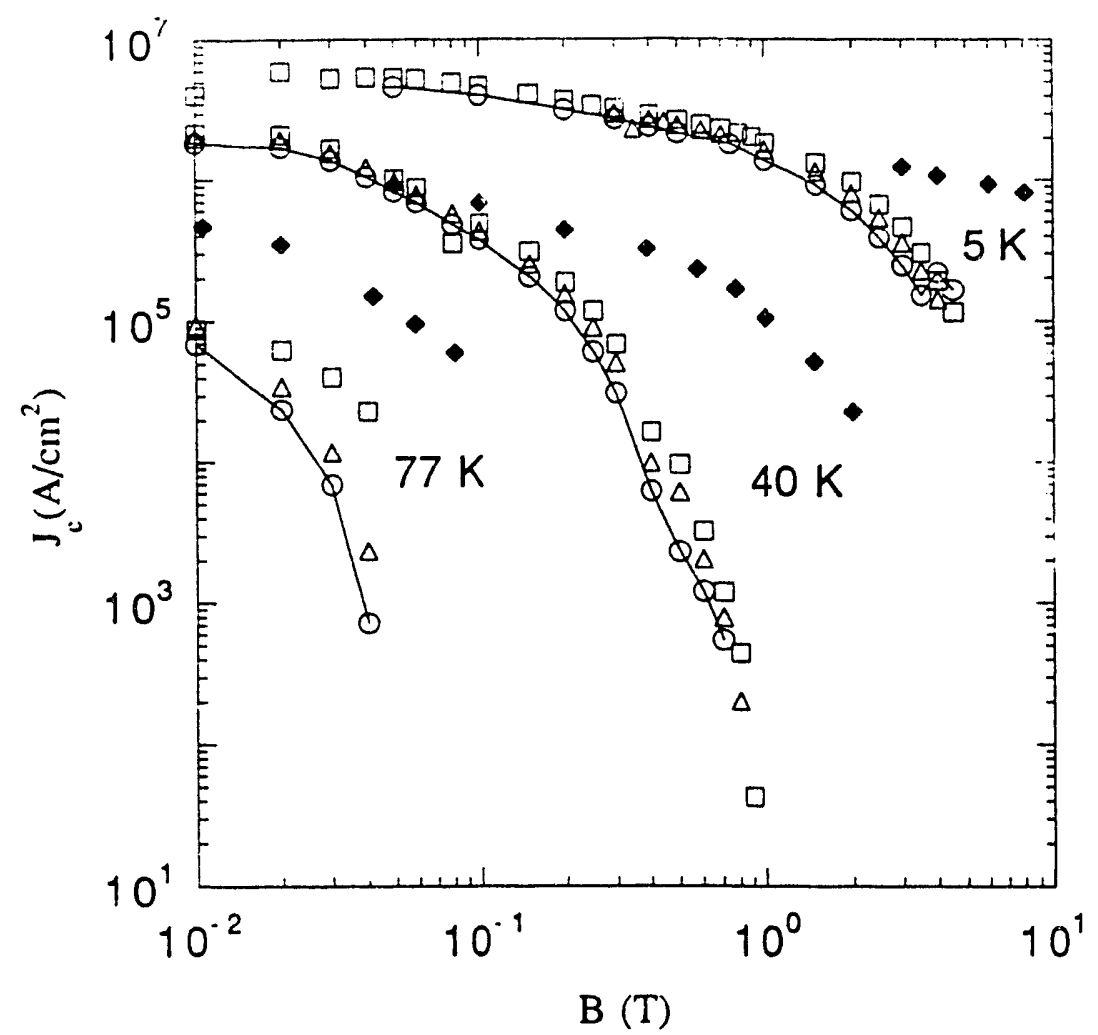

Fig. 8. Magnetic (open symbols) and transport (solid diamonds) determinations of $J_{c}$ for an epitaxial film made and patterned by STI into a square (for magnetic $J_{c}$ ) and into a four-probe layout (for transport). Magnetic results for the square (open squares) scaled properly when scribed into quarters (open triangles) and again into sixteenths (open circles) for the lower temperatures of $5 \mathrm{~K}$ and $40 \mathrm{~K}$, verifying that $J_{c}$ determined from the Bean model (which works best on thin fums, because full-flux penetration occurs at fields of 100-300 G) was valld. There is good agreement in $J_{c}$ at lower $H$ and $T$, but at higher fields and at $77 \mathrm{~K}$, the lower $J_{c}$ from the magnetic measurements is related only to the significantly greater effective-voltage sensitivity of the magnetic measurements and the power-law current-voltage characteristics (which were also measured by transport). 
Josephson interlayer coupling. These results are of cruclal significance for moderate-fleld applications of superconductors at relatively high temperatures, as shown by the irreversibility crossovers in Fig. 9.

We are pursuing low-tempcrature, one-step processing of superconductors made by deposition techniques because it has several advantages: better substrate compatibility; smoother surfaces; and the ease of continuous deposition of long wires and tapes. Our approach is to demonstrate its feasibility for the B1- and Tl-based cuprates, which display a high-degree of orientation on flat nonepitaxial substrates. We began with $\mathrm{Bi}_{2} \mathrm{Sr}_{2} \mathrm{CaCu}_{2} \mathrm{O}_{\mathbf{x}}$. because $\mathrm{Bl}$ has a lower volatility than does $\mathrm{Tl}$, and obtained superconducting films with $\mathrm{T}_{\mathrm{c}}$ $\approx 70 \mathrm{~K}$ and $J_{c}(10 \mathrm{~K}, \mathrm{H}=0)$ of $2 \times 10^{4} \mathrm{~A} / \mathrm{cm}^{2}$. The difficulty of achieving correct and reproducible compositions in our on-axis sputtering system is primarily due to resputtering of $B 1$ by negative oxygen ions accelerated by electric fields normal to the target surface. Resputtering can be reduced by placing substrates off-axis or by much higher system pressures, but these result in a significantly reduced deposition rate. We have determined how to avoid this problem by use of a lower pressure of a stronger oxidant or by modifying the sputtering geometry.

To efficiently determine the proper target composition for given deposition conditions, a new sputtering system with four independently controllable guns and the capability for in-situ X-ray fluorescence compositional analysis has been built. This system allows us to measure and control composition during growth. Because of the angle and position of the guns with respect to the substrate, a $40 \%$ variation in film thickness occurs along a $5-\mathrm{cm}$ line parallel to the gun axis. We invented a novel technique to achieve $\pm 1 \%$ thickness variation along this line and $5 \%$ variation over a $20-\mathrm{cm}^{2}$ area. By rotating the substrate and using novel techniques developed at ANL, we have good reason to believe that compositional uniformity can be maintained within a few percent over such an area, but that contention must be verified.

We have also prepared standards for quantitative compositional analysis in our X-ray fluorescence systems and for SEM and TEM studies. These splat-quenched materials are amorphous and exhibit variations of less than $2 \%$ in $\mathrm{Bl}$, $\mathrm{Sr}$, and $\mathrm{Cu}$ compositions (less than $3 \%$ for $\mathrm{Ca}$ ); they are also free of second-phase particles, which allows for accurate determination of overall composition.

The phase diagram (in oxygen) near the 2212 BSCCO compound has been evaluated by systematically varying the concentration of each element and identifying the phases by electron microscopy and $\mathrm{X}$-ray diffraction. Ranges of solubility and the corresponding changes in lattice parameters have also been determined. Most impurity phases had little effect on the superconducting properties, with the notable exception of $\mathrm{Bi}_{2} \mathrm{Sr}_{2} \mathrm{Ca}_{1} \mathrm{O}_{\mathrm{x}}$, which is a semiconductor that impairs resistive transitions. Considerable substitution between $\mathrm{Sr}$ and $\mathrm{Ca}$ in 2212 grains was found in SEM and TEM studies, with slight excesses of $\mathrm{Ca}$ yielding improved resistive transitions. Furthermore, it is observed that under most conditions, the $\mathrm{Bl}$ is partitioned between the 2212 and 2201 phases in order to most effectively combine with the avallable $\mathrm{Sr}$ and $\mathrm{Ca}$. Variations in the density of 2201 intergrowths as a function of composition was also revealed by TEM, suggesting that there is less range of solubility in the 2212 phase than measured, with the larger deviations being accommodated by an increased number of intergrowths. 


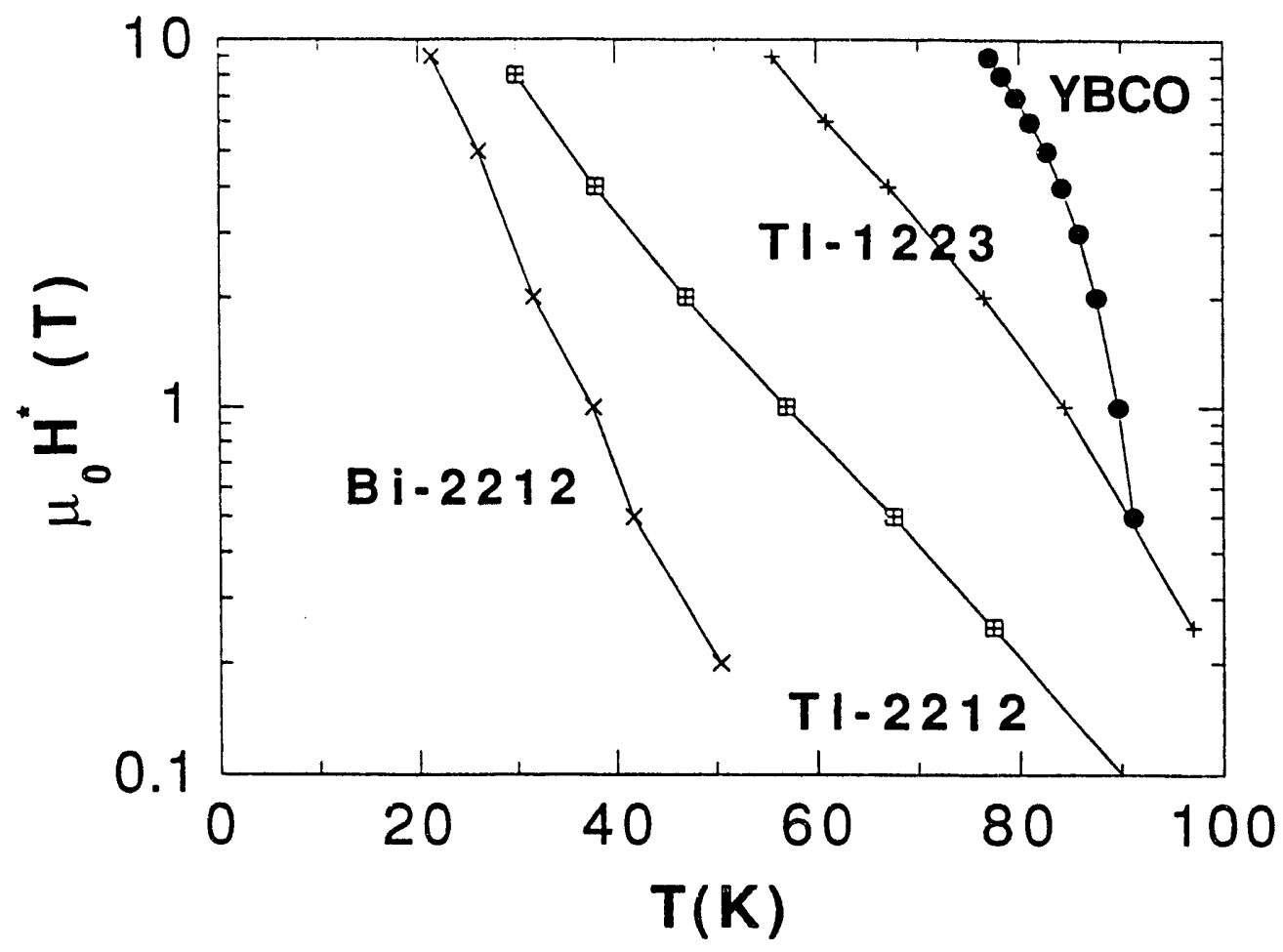

Fig. 9. Irreversibility crossovers for various high-temperature superconductors indicate the approximate regions in $H$ and $T$ for currentcarrying applications. On this line, $J_{c}$ would be $<100 \mathrm{~A} / \mathrm{cm}^{2}$ at a reasonable criterion of $1 \mathrm{mV} / \mathrm{cm}$. They show why $\mathrm{YBa}_{2} \mathrm{Cu}_{3} \mathrm{O}_{x}$ has the best superconducting properties in a magnetic field, but also that small interlayer spacing is a key to finding good alternatives that do not exhibit the grain-boundary weak links associated with $\mathrm{YBa}_{2} \mathrm{Cu}_{3} \mathrm{O}_{x}$. For the present. $\mathrm{TBBa}_{2} \mathrm{Ca}_{2} \mathrm{Cu}_{3} \mathrm{O}_{x}$ appears to be the best choice because of its high $T_{c}$.

In the course of these studies, a proprietary annealing sequence has been developed that yields improved superconducting properties. As shown in Fig. 10, an additional pretreatment step yields a significantly sharper resistive transition and higher zeroresistance temperature than does a standard anneal in oxygen. Magnetometer data have shown that the temperature for the onset of diamagnetism is not changed, but that the amount of 2212 phase formed is increased. Thus, it is apparent that the processing sequence promotes the formation of well-connected 2212 grains.

\subsubsection{Status}

Our program to develop low-temperature, one-step processing of high-temperature superconductors will take two parallel paths. Our efforts to establish composite-target sputtering of $\mathrm{Bi}_{2} \mathrm{Sr}_{2} \mathrm{CaCu}_{2} \mathrm{O}_{\mathrm{x}}$ will continue, emphasizing improved compositional control by minimizing $\mathrm{Bi}$ resputtering through the use of low-pressure ozone oxidation and a cylindrical-hoop sputtering geometry. Our experiments indicate that an equivalent oxidation of molecular oxygen can be attained by use of only about $1 \%$ of the stronger oxidant, ozone, with a significant reduction in $\mathrm{BI}$ loss. In the second technique, substrates 


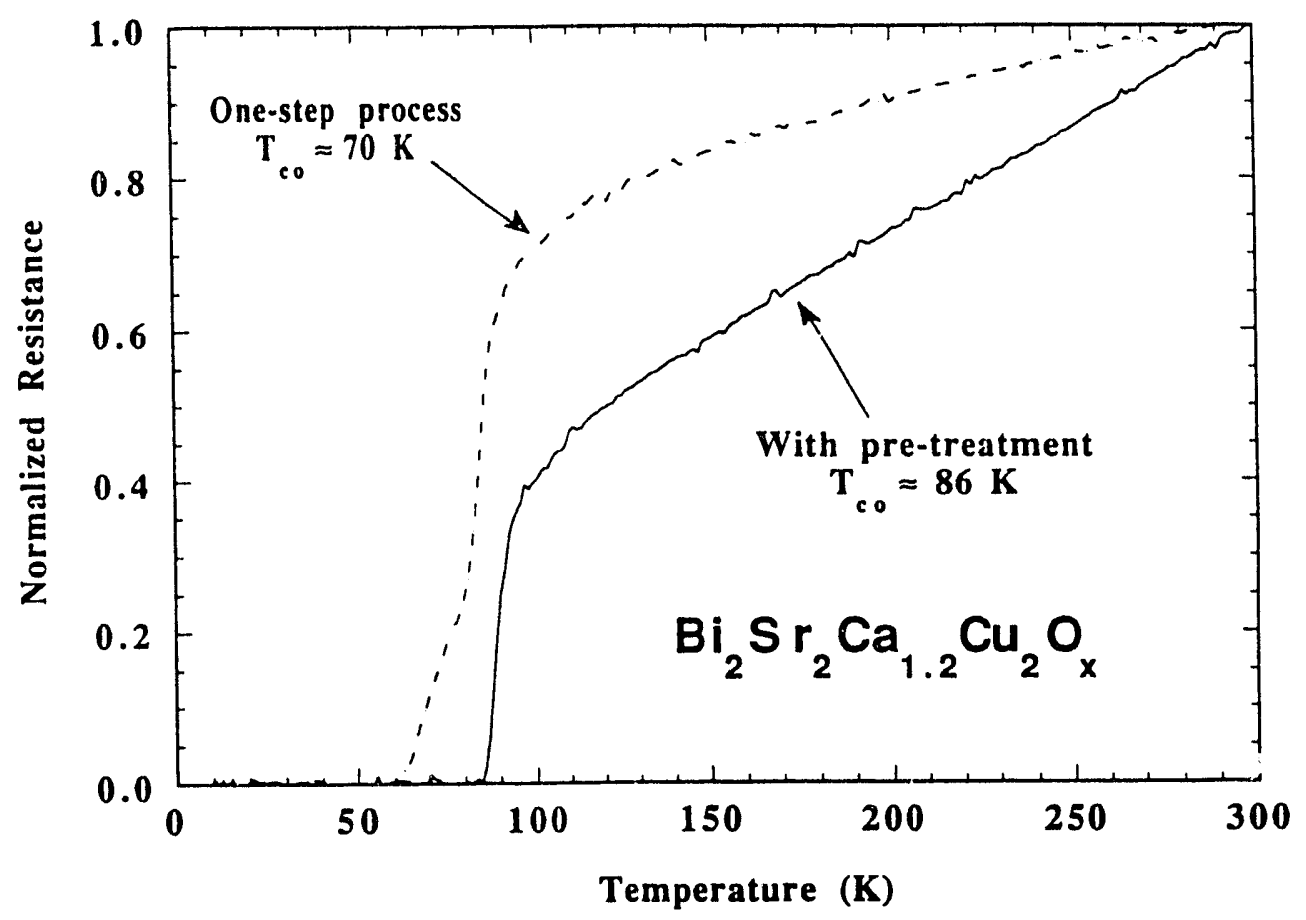

Fig. 10. Results of a proprietary annealing sequence on resistive transttions of bulk $\mathrm{Bi}_{2} \mathrm{Sr}_{2} \mathrm{CaCu} \mathrm{C}_{2} \mathrm{O}_{x}$. Magnetometer data show that the onset temperature of diamagnetism is not changed, out that the amount of 2212 phase formed is increased.

are placed above the open end of a cylindrical-hoop target, in which the energetic ions are confined to the hoop plane while the target atoms are sputtered at an average angle of 20 to 45 degrees to coat the substrates. The deposition rates in preliminary tests are $\approx 30$ times greater than in off-axis planar sputtering and the $\mathrm{E} 1$ loss is $50 \%$ of that in on-axis sputtering.

Our previous studies have shown a variation in composition of the 2212 phase with some substitution between $\mathrm{Ca}$ and $\mathrm{Sr}$, indicating antisite disorder. High-resolution analytical electron microscopy studies will be performed in an attempt to gain insight on the extent of antisite substitution for each of the elements. For example, our previous studies also suggest that the extent of substitution may be overestimated and that a significant percentage of compositional deviations may be accounted for by intergrowths. These future studies will be almed at measuring the true composition of the 2212 phase, excluding intergrowths, and evaluating the extent of antisite substitution.

Studies of the effects of impurity phases in BSCCO will continue. A commonly observed impurity phase, $\mathrm{Cu}_{24} \mathrm{Sr}_{14-\mathrm{x}} \mathrm{Ca}_{\mathrm{x}} \mathrm{O}_{\mathrm{y}}$, has an indirect effect on properties. Although this phase tends to form only under specific conditions, it is very difficult to eliminate by annealing and it consumes metallic elements vital for complete transformation to the 2212 phase. Studies will try to determine how that phase forms and to further evaluate the effects of phase formation and competition on superconducting properties, particularly zeroresistance temperatures and magnetically measured $T_{c}$ of the superconducting grains. 
Studies of the $\mathrm{Tl}$-based cuprates will begin with $\mathrm{TlBa}_{2} \mathrm{Ca}_{2} \mathrm{Cu}_{3} \mathrm{O}_{\mathrm{x}}$, a material that is extremely promising for moderate-temperature, high-field conductor applications because of its favorable irreversibility behavior caused by lower anisotropy. This material has the best potential for achieving the interim goals of our conductor program: $J_{c}=10^{4} \mathrm{~A} / \mathrm{cm}^{2}$ at $35 \mathrm{~K}$ and $2 \mathrm{~T}$. To verify the conclusions of our recent determination of the irreversiblity behavior, $\mathrm{J}_{\mathrm{c}}$ measurements are needed in samples that do not contain grain-boundary weak links. We plan to make epitaxial films by determining the conditions for postannealing in our processing chamber, which has in-situ $\mathrm{X}$-ray fluorescence and diffraction capabilities, and the potential for pressures to retain this $T l$. We will then measure $\mathrm{J}_{\mathrm{c}}$ at high temperatures (up to $77 \mathrm{~K}$ ) and moderate fields (up to $8 \mathrm{~T}$ ). Having established how transport measurements of $J_{c}$ are related to contactless magnetic measurements. we will use these measurements to study the effect of sequential neutron irradiation to add pinning sites.

Initially with epitaxial films of $\mathrm{Tl}_{2} \mathrm{Ba}_{2} \mathrm{CaCu}_{2} \mathrm{O}_{x}$ from STI, we will alternate between increased neutron dosages and magnetic measurements of $\mathrm{J}_{c}$. Similar films will be patterned and irradiated for studies of concomitant changes in irreversibility behavior. The extension to epitaxial films of $\mathrm{TlBa}_{2} \mathrm{Ca}_{2} \mathrm{Cu}_{3} \mathrm{O}_{\mathrm{x}}$ will begin when they are available.

We will also begin to develop low-temperature, une-step processing of the Tl-based cuprates, which will include the use of composite targets and the most promising sputtering geometry, i.e., planar, hollow-cathode, or cylindrical-hoop. For this, we will rely on the expertise gained in our established program for the one-step processing of $\mathrm{Bi}_{2} \mathrm{Sr}_{2} \mathrm{CaCu}_{2} \mathrm{O}_{\mathbf{x}}$.

Phase diagram studies will be extended to low pressures and to the TBCCO system. Focal points of these studies will be the solubility limits of each superconducting phase in the system and the effects of stoichiometry deviations on properties. Initial studies in the TBCCO system will concentrate on phase equilibria and impurity phases near the 1223 phase. Subsequent work will widen the scope of the program to include the other superconducting phases.

In addition, a technique to produce patterned samples from bulk pleces will be used to measure $J_{c}$ in BSCCO. The effect of impurity phases and variations in composition of the 2212 phase on $J_{c}$ will be evaluated. Our new processing sequence, which is compatible with powder-in-tube techniques, will also be evaluated for its effect on $J_{c}$ because it offers potential for improving current carrying capability in wires. Consequently, bulk and wire samples will be prepared with this technique, and magnetic and transport measurements of $J_{c}$ will be made as a function of magnetic field.

\subsection{Interactions}

We have sent more extruded YBCO wires with Ag additions to Professor Paul McGinn of the University of Notre Dame for zone-melting experiments. Microstructures of the zonemelted specimens consist of large Ag and 211 precipitates within YBCO grains. The Ag precipitate size decreased with diminishing Ag additions. Critical current densities of more than $5500 \mathrm{~A} / \mathrm{cm}^{2}$ were measured in applied fields of $0.8 \mathrm{~T}$ at $77 \mathrm{~K}$. Transport properties significantly degraded when Ag contents exceeded 5 vol.\%. These results are in contrast to sintered substrates in which no $J_{c}$ degradation has been observed up to 15 vol.\% Ag (McGinn et al., 1990). 
Our collaboration with Astronautics of Milwaukee, WI. is intended to explore the use of ceramic YBCO bars as current leads for a Gifford-McMann refrigerator. The design of this refrigerator provides two potential areas for application of bulk high- $T_{c}$ superconductors. The operational temperature of the first stage is 15 to $50 \mathrm{~K}$. The high- $\mathrm{T}_{c}$ superconductor current lead would provide $150 \mathrm{~A}$ in an 0.01-T field. The second region would operate below $20 \mathrm{~K}$ in an external field of $0.1 \mathrm{~T}$.

We are continuing to interact with Professor Deborah Chung of the State University of New York at Buffalo in the development of carbon-fiber high- $T_{c}$ composites. Transport $J_{c}$ at $77 \mathrm{~K}$ remains modest, but mechanical properties are excellent.

We have sent more than $1 \mathrm{~kg}$ of YBCO powder to the Naval Surface Warfare Center (NSWC) in Silver Spring, MD. They add Ag by a melt process and return the powder to us for processing of wires and colls. These samples were sintered under reduced total pressure conditions and a transport $\mathrm{J}_{\mathrm{c}}$ of about $750 \mathrm{~A} / \mathrm{cm}^{2}$ was obtained.

In a collaboration with SuperconiX of St. Paul, MN, we have evaluated several BSCCO single crystals. The $T_{c}$ values were $\approx 89 \mathrm{~K}$, and TEM confirmed that large, relatively perfect crystals could be separated from the frozen mass of flux.

A collaboration hetween Supercon Technologies of Grass Lake, MI, and ANL has been completed. After experimenting in the manufacture of sheathed superconductor rods, the company has become inactive in the field. The work at ANL included synthesis of powders, radiography of manufactured rods, specification and application of heat treatments, $J_{c}$ testing, and evaluation of results and offering of recommendations. Specific recommendations for a new set of samples were given. Supercon Technologies accepted the plan. but has not otherwise responded.

The initial work between High-Tc Superconco of Lambertville, NJ, and ANL was described in the previous report (Poeppel et al., 1990). The company stated that on the basis of the findings, the effort to make filamentary superconductors would continue. Recently, the company reported success in spinning fibers containing substantial loadings of high-temperature superconductor powders. Samples for thermal processing and characterization are expected to be received at ANL in the near future.

Quench-melt-growth-processed samples produced at ANL have exhibited good magnetic levitation and Tux pinning. Superconducting bearings made from these samples in collaboration with the United Technologies Research Center, East Hartford, CT, achieved a rotational speed of $200,000 \mathrm{r} / \mathrm{min}$ and a coefficient of friction of $8 \times 10^{-6}$. Such a low coefficient of friction has important implications for the possible use of a permanent magnet/high- $T_{c}$ bearing in a flywheel used for energy storage (Weinberger et al., 1991a).

Within this program, we have offered to characterize the superconducting properties of films made at Sandia and Lawrence Berkeley national laboratories and have sent our TBCCO films to the Solar Energy Research Institute for analysis. The compositions of BSCCO and YBCO films made at Lawrence Berkeley have been verified by our X-ray fluorescence. There are three pilot center agreements (with TRW of Redondo Beach, CA, on TEM microstructure: with Microelectronics and Computer Technology Corporation (MCC) of Austin, TX, on continuous deposition of wires and tapes by hollow-cathode sputtering; and with STI of Santa Barbara, CA, on processing of TBCCO). We also have an agreement with Corning. Inc. 
of Corning, NY, to provide thin flexible substrates of zirconia, and with Superconductive Components (Columbus, $\mathrm{OH}$ ) to provide sputter targets by the HIP process. Neutron irradiation will be done at the Atominstitüt in Vienna. Austria. In addition, in-situ X-ray. thin-film patterning, and high-resolution secondary ion mass spectrometry analyses are provided through the NSF Science and Technology Center for Superconductivity (involving the Untversity of Chicago, Northwestern University, and the University of Illinois at UrbanaChampaign). The Center has also provided graduate students and ready access to expertise on the metal-oxide chemical vapor deposition deposition of high- $T_{c}$ superconductors. A number of other interactions are under discussion with industrial and university partners.

Several collaborative experiments have been performed at IBM (Yorktown Heights. NY) and the Materials Science Division of ANL over the past year. These experiments have explored the improvements in magnetic superconducting properties of YBCO achieved by irradiation with two different particles. High-energy protons $(3 \mathrm{MeV})$ were used to increase the $J_{c}$ in single-crystal specimens of YBCO. The changes in superconducting properties were measured at IBM, and the microstructural damage created by the irradiations was investigated at ANL by electron microscopy. These combined techniques on the same irradiated crystal are unique. The irradiation resulted in substantial increases in $J_{c}$, with minimal degradation of other properties and minimal microstructural damage. From these measurements, substantial progress was made in understanding the physics behind the increase in $J_{c}$ produced by the introduction of irradiation defects that pin magnetic flux lines, and in understanding the defect state of thin films because the critical currents achieved in proton-irradiated crystals are comparable to those of the best films. The work on proton irradiation of YBCO has resulted in three papers (Civale et al., 1990; Kirk, 1991; Civale et al., 1991a), a fourth that is now in preparation, and four conference presentations.

A second type of irradiation experiment, with very-high-energy heavy ions $(580 \mathrm{MeV}$ $\left.\mathrm{Sn}^{+}\right)$, has recently yielded quite exciting results. The defect structure is unique: linear tracks of damage are seen through the entire crystal, as measured by TEM. Magnetic measurements at IBM show that this microstructure produces particularly strong pinning at high temperatures and high fields: in fact, the critical currents in this technologically important regime are higher than those of thin films. This result, only a few months old, has already been reported in two conferences, ard has been submitted to Physical Review Letters (Civale et al., 1991b). From the irradiation standpoint, this result is important because the pinning defects can be unambiguously identified as the ion tracks, due to the dependence of critical current on the direction of magnetic field.

The funds made avallable at ANL in the past year from this agreement were used for operating materials and services related to this work. Additionally, a one-day workshop on Proton Irradiation Effects in YBCO was supported, including travel for four invited speakers, two of whom were from IBM. A longer visit to ANL from two collaborators at IBM was supported, and followed later by a three-day visit of M. A. Kirk to IBM, which was supported by IBM.

The electron microscopy work to fully characterze the damage due to both proton and heavy-ion irradiation is incomplete. More conventional TEM is needed, and the more difficult-but potentially more illuminating-high-resolution electron microscopy will be attempted. Electron-energy-loss spectroscopy will also be attempted on individual irradiation defects to investigate their electronic natures and understand how they pin magnetic 
flux lines. Some of this new work will be performed on microscopes and instruments located at Northwestern University and Oxford University, and hence will incur some additional expenses.

Hollow-cathode sputtering is being explored, in collaboration with MCC as a method to produce continuous lengths of tapes and wires of high- $T_{c}$ superconductors. Using a sputter-gun from $\mathrm{MCC}$, we have developed low-cost $\mathrm{Bi}_{2} \mathrm{Sr}_{2} \mathrm{CaCu}_{2} \mathrm{O}_{\mathrm{x}}$ targets and studied thick films made by this process, which after post-annealing showed $T_{c}$ values of $60-70 \mathrm{~K}$ and $\mathrm{J}_{\mathrm{c}}(10 \mathrm{~K}, \mathrm{H}=0)$ of $3000 \mathrm{~A} / \mathrm{cm}^{2}$. In doing so, a potential benefit has been discovered: the substrates are significantly heated by the plasma to temperatures near that required for in-situ deposition of $\mathrm{Bi}_{2} \mathrm{Sr}_{2} \mathrm{CaCu}_{2} \mathrm{O}_{x}$, so that one-step coating of a superconductor is a real possibility. Compared to planar sputter sources, a further advantage of such heating is that it is applied to the growing surface, not through the substrate, and has an inherent symmetry around wire or tape conductors. We are presently studying resputtering and its effect on composition: preliminary indications are that a larger-diameter hollow cathode and activated oxygen may be beneficial. In a follow-up program, we propose to use ozone and larger target diameters to study in-situ growth of conductors $>10 \mathrm{~cm}$ in length.

In a collaborative program with STI, we have mostly achieved our first goal of developing sputtered precursors of $\mathrm{Tl}_{2} \mathrm{Ba}_{2} \mathrm{CaCu}_{2} \mathrm{O}_{x}$ into high-quality films by using a subsequent anneal at STI with their proprietary process. A new varlable-temperature, multiplesubstrate holder in our three-gun deposition system allowed us to send more than one dozen precursors that have exhibited outstanding $T_{c}$ values of $100-105 \mathrm{~K}$ and $Q$ as high as 12,000 for resonators patterned from these films. The $Q$ values compare favorably with those obtained by STI using laser ablation deposition, and the smoother surfaces of the sputtered films should prove beneficial in making multilayer structures. Work has begun on the other goals of the initial one-year contract: comparing dry sputter-etching of films at ANL with the chemical etch used at STI; and studying the effects of neutron irradiation on the critical-current carrying capacity of these films. In the second year, we propose to improve the reproducibility and uniformity of sputtered precursors for $\mathrm{Tl}_{2} \mathrm{Ba}_{2} \mathrm{CaCu}_{2} \mathrm{O}_{\mathrm{x}}$ films using the multigun sputter system with our recently invented system to provide uniformity from each gun. The objective is to avoid impurity phases and defects to improve the highfrequency properties for use in devices made at STI and the $\mathrm{J}_{\mathrm{c}}$ for conductor applications. A new initiative will use the STI proprietary processing and expertise to make epitaxial films of the extremely promising $\mathrm{TlBa}_{2} \mathrm{Ca}_{2} \mathrm{Cu}_{3} \mathrm{O}_{\mathbf{x}}$.

The technical part of the program with Conductus, Inc., of Sunnyvale. CA, and ANL to develop tunnel-junction Josephson devices is just beginning. The goals are to develop allthin-film Josephson tunnel junctions using medium-temperature oxide superconductors. which have demonstrated excellent characteristics in recent point-contact tunneling studies at ANL. Such devices are crucial in developing certain low-temperature electronic control instrumentation. The collaboration includes subcontracts to the illinois Institute of Technology, Stanford University, and Oregon State University.

A collaborative program to improve the fracture toughness and strength of oxide superconcilictors has begun between ANL, Illinois Superconductor Corporation of Evanston, IL, and ivorthwestern University. Argonne will develop prototypic YBCO having high fracture toughness and thermal shock resistance. Illinois Superconductor will develop and design a superconducting probe for cryogenic thermal transducers, test samples, and prototypes for service environments, and will evaluate the technical factors affecting device performance. 
Northwestern University will measure the stresses and perform stress analyses of the probe support materials. In the past month, a research assoclate has been hired, and unprocessed and processed YBCO wires have been received. The superconductors will be sintered at ANL by various thermal treatments, with and without second-phase additives. Properties will be tested and the work will proceed until suitable candidates have been found.

The collaboration between Superconducting Products Company, Downers Grove, IL. and ANL has involved fabrication of Ag-clad wires. The Sr-deficient 2212 BSCCO powder synthesized at ANL was packed into Ag tubes and subsequently drawn to a diameter of $1 \mathrm{~mm}$. Specimens were subjected to various thermomechanical treatments. Processing parameters that were controlled included the amount of reduction by rolling, as well as firing conditions such as temperature, hold time, and atmosphere. To date, 90 separate sets of processing conditions have been tested, and the most significant parameter was found to be processing temperature. Thermal analysis data suggested that the optimum processing temperature is close to the peritectic melting point of the 2212 compound. $J_{c}$ values of 30,000 and $10,000 \mathrm{~A} / \mathrm{cm}^{2}$ were measured for a $1-\mathrm{cm}$-long tape and $60-\mathrm{cm}-$ long coil, respectively $\left(4.2 \mathrm{~K}, 1-\mu \mathrm{V} / \mathrm{cm}\right.$ criterion). The $J_{c}$ did not change in fields up to $50 \mathrm{mT}$ or during a thermal cycle between room temperature and $4.2 \mathrm{~K}$; however, a significant decrease in $J_{c}$ was measured when electrical leads were removed and reattached again to the samples.

The purpose of the agreement between MagneTek of Los Angeles, CA, and ANL is to develop and build motor-winding prototypes. Materials development is focused on obtaining $\mathrm{J}_{\mathrm{c}}$ values of at least $10^{4} \mathrm{~A} / \mathrm{cm}^{2}$ in thick films. Novel microstructures and high $\mathrm{J}_{\mathrm{c}}$ values are produced by melt-recrystallization processing. Although zone-melting is slow, it may be a viable process for manufacturing motor windings because of their small areas. An infrared heater was used to zone-melt 2212 BSCCO thick films on single-crystal MgO suiustrates. Highly textured 2212 can be grown at slow speeds $(\approx 1 \mathrm{~cm} / \mathrm{h}$ or lower). Microstructural analysis revealed that long crystallites aligned along the solidification path. $T_{c}$ values of $80 \mathrm{~K}$ were measured for many of these specimens. $J_{c}$ values at $4.2 \mathrm{~K}$ were greater than $7500 \mathrm{~A} / \mathrm{cm}^{2}$ and were limited by contact resistance, not by the performance of the thick films.

We have been working with the NSWC on conductor development based on powder-intube processing. BSCCO powders made at ANL were packed in Ag tubes at NSWC and swaged into wires. These samples were sintered at ANL under varying conditions of temperature and oxygen pressure. These wires exhibited $J_{c}$ values of $\approx 25,000 \mathrm{~A} / \mathrm{cm}^{2}$ at $4.2 \mathrm{~K}$ in a self-field. The sintered wires will be rolled into tapes at NSWC, and further heat treatments will be done to enhance the $J_{c}$ values.

Argonne is working with Ceracon Industries of Sacramento. CA, to develop and test electrical leads made from high-temperature superconductors. Ceracon uses its proprietary process to form the powders supplied by us into wires, cylinders, and other commercial shiapes suitable for leads. We measure the ability of Ceracon's current leads to carry current at various temperatures in the presence of various magnetic fields.

In the area of powder synthesis, calcination, and characterization, we are working with two companies: SSC. Inc. (Bothell, WA) and Rhône-Poulenc (Cranbury, NJ). Powders 
synthesized by proprietary wet-chemical techniques at these two companies are calcined and characterized by us. We have optimized the conditions for processing these powders.

We have transferred our developed YBCO synthesis technology to a number of companies. Superconductive Components is using the low-pressure calcination technique and, as a result, has produced superior powders for sputtering targets.

Our interaction with Northwestern University is progressing well. Using their new atomic resolution analytical electron microscope, we are able to identify unambiguously new flux-pinning centers in YBCO. Our results strongly indicate that the major flux-pinning defect in YBCO is a copper planar defect. We have observed a clear link: defects in the matrix pin flux, whereas grain boundary defects do not pin flux.

For a collaborative project between ABB. Inc. of Windsor, CT, and ANL, a system study for small-scale superconducting magnetic energy storage (SMES) has been completed and the results published (Palmer et al., 1990; Hull et al., 1991). From an economic and fabrication standpoint, solenoidal small-scale SMES systems are desired. External magnetic fields of small-scale solenoids are comparable with other electrical equipment in utility substations. Cold-mass-constrained liquid-helium-cooled (LHe) SMES systems are unlikely to be efficient in diurnal energy storage applications.

A number of potential applications exist for small-scale LHe SMES, mainly for improving the reliability of power delivery, either in the utility grid itself or on the customer side of the meter. In these applications, efficiency is not critical. Voltage sags and momentary (several-cycle) outages can seriously disrupt automated factories and other critical technologies that require reliable and continuous power input. Other utility needs include damping of power oscillations and enhancement of electrical stability during transmission-line faults and trips. An advantage of small-scale SMES is mobility: as demands on the utility or the power user change, the SMES can be moved, thus providing more flexdbility for future expansion of the delivery system.

We conclude that LHe SMES is the only near-term possibility. One of the earliest applications of high- $\mathrm{T}_{\mathrm{c}}$ superconductors to this technology will probably be in current leads. As high- $T_{c}$ wire is developed in the next several years, it seems likely the first HTSMES will operate in LHe and then shortly thereafter at $20 \mathrm{~K}$, cooled by either liquid hydrogen or gaseous helium. Before HT-SMES will operate at $77 \mathrm{~K}$, significant advances in high- $T_{c}$ technology must be made.

A project with Westinghouse to design, fabricate, and test a vapor-cooled current lead. composed partially of high-temperature superconductor, has been completed and the results published (J. L. Wu et al., 1991). The lead consisted of a lower superconducting portion and an upper copper metal portion. The lower portion, made up of ceramic Y-Ba$\mathrm{Cu}-\mathrm{O}$ bars, operated at a temperature of less than about $40 \mathrm{~K}$ and remained supercon-

ducting up to a total current of about $2000 \mathrm{~A}$. The entire assembly was encased in a plastic shroud so that helium vapor escaping from the cryogenic apparatus passed along the length of the lead and cooled it, especially the warm copper conductor near the top. The helium boll-of from the lead was about $40 \%$ less than the theoretical minimum for a conventional lead of identical current rating made from normal conductor. 
ANL and the Reliance Electric Company are working together to demonstrate the applicability of high- $\mathrm{T}_{\mathrm{c}}$ superconductors in electric motors. The goal of this collaboration is to bulld a 1-hp salient pole, synchronous motor with high- $T_{c}$ field windings and copper stator windings. This design offers several advantages over other designs, including minimal AC magnetic fields at the superconductor, modular superconductor coils, and minimal requirements for the superconductor. Reliance Electric has already designed and constructed the normal components of a highly instrumented test bed motor and has provided ANL with drawings of the necessary superconductor colls. In addition to demonstrating the applicability of high- $\mathrm{T}_{c}$ superconductors in electric motors, the instrumented motor will permit the investigation of several important engineering parameters, including the effect of AC magnetic fields on critical current density and the effect of self-fields on the ability to create a magnetic field in the air gap of an iron core motor. To examine these effects. ANL has rrovided Reliance Electric with numerous small test colls and several multilayer coils made from YBCO. One of the multilayer colls was used by Rellance in a small motor that operated at $1300 \mathrm{r} / \mathrm{min}$ during a demonstration for EPRI representatives.

To date, tests by Reliance have shown that coll performance has improved by an order of magnitude, but must be further improved to make possible construction of the demonstration motor. The field coils for the demonstration motor will require a critical current density of $500 \mathrm{~A} / \mathrm{cm}^{2}$ in a magnetic field of $400 \mathrm{G}$. Fabrication of a superconducting motor that generates useful power will require a critical current density of $\approx 10,000 \mathrm{~A} / \mathrm{cm}^{2}$ in a magnetic field of several $\mathrm{T}$. Efforts to produce the necessary coils are proceeding in several directions. We are continuing to produce multilayer YBCO colls by extrusion, focusing on the reduction of residual carbon. Total carbon analysis on a recent, multilayer YBCO coil showed the wire had $\approx 0.18 \mathrm{wt} . \%$ carbon, a significant concentration that must be reduced. In a parallel effort, we are using the powder-in-tube method to process TCBCO and BSCCO (2223). Like extrusion, this method allows for production of the long lengths of superconductor necessary for the coils, but presently seems more promising for increasing critical current density. To date, critical current densities at $77 \mathrm{~K}$ in self-fields have been as high as $\approx 2000 \mathrm{~A} / \mathrm{cm}^{2}$ in short lengths of TCBCO specimens and $1000 \mathrm{~A} / \mathrm{cm}^{2}$ in $\mathrm{BSCCO}$ samples. Current efforts are concentrating on both improving the critical current density and producing coils by the powder-in-tube method.

A project with United Technologies to understand the basic levitation force phenomena associated with superconducting magnetic bearings and to develop these bearings for applications in rotating machinery completed a second year with a number of results published (Chang ex al., 1990; Weinberger et al., 1990; Basinger et al., 1990; Weinberger et al., 1991b; Cha et al., 1991. Prototype bearings using high- $T_{c}$ superconductors have been demonstrated. Levitation pressures obtainable between permanent magnets and melttextured $\mathrm{Y}-\mathrm{Ba}-\mathrm{Cu}-\mathrm{O}$ are on the order of $100 \mathrm{kPa}$, which is competitive with those pressures produced by gas-film bearings, the most likely alternative technology for cryogenic machinery. We have experimentally demonstrated extremely low magnetic drag in a thrust bearing configuration. The low drag values have significant benefits in several important applications. 


\section{References}

T. Aselage and K. Keefer. J. Mater. Res. 3, 1279 (1988).

U. Balachandran, S. L. Morissette, R. A. Russell, S. E. Dorris, and R. B. Poeppel, in "High Temperature Superconducting Compounds III," eds. S. H. Whang, A. DasGupta, and E. W. Collings (Metallurgical Society, Warrendale, PA, 1991a), in press.

U. Balachandran, R. A. Russell, S. L. Morissette, T. J. Brent, and R. B. Poeppel, Ceram. Trans., in press (1991b).

S. A. Basinger, J. R. Hull, and T. M. Mulcahy, Appl. Phys. Lett. 67, 2942 (1990).

A. C. Biondo, J. S. Kallend. A. J. Schultz, and K. C. Goretta, in Proc. 2nd World Congress on Superconductivity, Houston, TX, ed. R. D. Kane (World Scientific, Singapore, 1991), in press.

D. Cahen, Z. Moisi, and M. Schwartz, Mater. Res. Bull. 22, 1581 (1987).

Y. S. Cha, S. E. Dorris, J. R. Hull, and R. B. Poeppel, to be presented at the ASME Winter Annual Meeting, Dec. 1-6, 1991, Atlanta, GA.

Y. S. Cha, J. R. Hull, T. M. Mulcahy, and T. D. Rossing, J. Appl. Phys. 70 (1991), in press.

P.-Z. Chang, F. C. Moon. J. K. Hull, and T. M. Mulcahy, J. Appl. Phys. 67, 4358 (1990).

L. Civale, A. D. Marwick, M. W. McElfresh, T. K. Worthington, A. P. Malozemoff, F. H. Holtzberg. J. R. Thompson, and M. A. Kirk, Phys. Rev. Lett. 65, 1164 (1990).

L. Civale, A. D. Marwick, M. W. McElfresh, T. K. Worthington, A. P. Malozemoff, F. H. Holtzberg, C. Field, J. R. Thompson, D. K. Christen, and M. A. Kirk, in "Proc. XII Winter Meeting on Low-Temperature Physics, Cuernavaca, Mexico, Jan 13-16, 1991" (World Scientific, Singapore, 1991a) in press.

L. Ctvale, A. D. Marwick, T. K. Worthington, M. A. Kirk, J. R. Thompson, L. Krusin-Elbaum, Y. Sun, J. R. Clem, and F. H. Holtzberg, submitted to Phys. Rev. Lett. April, 1991b.

S. E. Dorris, J. T. Dusek, M. T. Lanagan, J. J. Picciolo, J. P. Singh, J. E. Creech, and R. B. Poeppel, Am. Ceram. Soc. Bull. 70, 722 (1991).

S. X. Dou, H. K. Liu, A. J. Bourdillon, M. Kviz, N. X. Tan, and C. C. Sorrell, Phys. Rev. B 40. 5266 (1989).

K. C. Goretta, J. G. Chen, Nan Chen, M. C. Hash and Donglu Shi, Mater. Res. Bull. 25, 791 (1990a).

K. C. Goretta, J. L. Routbort, A. C. Biondo, Y. Gao, A. R. de Arellano-López and A. DominguezRodriguez, J. Mater. Res. 5, 2766 (1990b).

S. Hirano, T. Hayashi, and M. Miura, J. Am. Ceram. Soc. 73, 885 (1990).

B. Hong and T. O. Mason. J. Am. Ceram. Soc. 74, 1045 (1991). 
J. R. Hull, S. M. Schoenung, D. N. Palmer, and M. K. Davis, Invited paper, CB-1, presented at the Cryogenic Engineering Conference. Huntsville. Alabama. June 11-14, 1991; to appear in Advances in Cryogenic Engineering. Vol. 37, ed. R. W. Fast (Plenum Press, New York, 1991).

M. Kirk. Mater. Res. Soc. Symp. Proc. 209, 743 (1991).

S. Koyama, U. Endo, and T. Kawai, Jpn. J. Appl. Phys. 27, L1861 (1988).

M. T. Lanagan, S. E. Dorris, J. P. Singh, K. C. Goretta, U. Balachandran, C. A. Youngdahl, J. T. Dusek, J. J. Picciolo, and R. B. Poeppel, J. Met. 42 [6], 16 (1990).

Y. L, Y. Gao, K. L. Merkle, H. Shi, and U. Balachandran, Mater. Res. Soc. Symp. Proc., Boston. MA. November 26-December 1, 1990, in press.

T. B. Lindemer, C. R. Hubbard, and J. Brynestad, Physica C 167, 312 (1990).

Y. Matsumoto, T. Abe, M. Tanaka. T. Tazawa, and E. Sato, Mater. Res. Bull. 23, 1241 (1988).

P. J. McGinn, N. Zhu, W. Chen, M. T. Lanagan, and U. Balachandran, Physica C 167, 343 (1990).

A. S. Nash, P. Nash, H. Shi, R. B. Poeppel, and K. C. Goretta, Supercond. Sci. Tech. 3, 556 (1990).

D. N. Palmer, J. R. Hull, T. M. Kuzay, and S. M. Schoenung, in Proc. 34th International Power Sources Symposium (Cherry Hill, NJ, June 1990), p. 5.

R. B. Poeppel et al., "Practical superconductor development for electrical power applications: Annual report for FY 1990," Argonne National Laboratory Report ANL-90/47 (1990).

B. Shao, A. Liu, Y. Zhou, J. Zhang, and J. Wang. Mat. Res. Bull. 24, 1241 (1988).

D. Shi, M. S. Boley, J. G. Chen, M. Xu, K. Vandervoort, Y. X. Liao, A. Zangvil, J. Akujieze, and C. Segre Appl. Phys. Lett. 55, 699 (1989a).

D. Shi, M. Tang, K. Vandervoort, and H. Claus, Phys. Rev. B 39, 9091 (1989b).

S. Shibata. T. Kitagawa, H. Okazaki, and T. Kımura, Jpn. J. Appl. Phys. 27, L646 (1988).

J. J. Simmins and R. L. Snyder, in "Superconductivity and Its Applications," ed. H. S. Kwok (Elsevier, New York, 1988), p. 89.

J. P. Singh, H. J. Leu, R. B. Poeppel, E. Van Voorhees, G. T. Goudey, K. Winsley, and D. Shi, J. Appl. Phys. 66, 3154 (1989).

B. R. Weinberger, L. Lynds, and J. R. Hull, Supercond. Sci. Technol. 3, 381 (1990).

B. R. Weinberger, L. Lynds, J. R. Hull, and U. Balachandran, Appl. Phys. Lett. (1991a), in press.

B. R. Weinberger, L. Lynds, J. VanValzeh, H. Eaton, J. R. Hull, T. M. Mulcahy, and S. A. Basinger, IEEE Trans. Magn. 27, 2415 (1991b). 
C.-T. Wu, K. C. Goretta, D. Shl, and R. B. Poeppel, in "High Temperature Superconducting Compounds III." eds. S. H. Whang, A. DasGupta, and E. W. Collings (Metallurgical Society. Warrendale, PA, 1991), in press.

J. L. Wu, J. T. Dederer, P. W. Eckels, S. K. Singh, J. R. Hull, R. Poeppel, C. A. Youngdahl, J. P. Singh, M. T. Lanagan, and U. Balachandran, IEEE Trans. Magn. 27, 1861 (1991). 


\section{Distribution for ANL-91/28}

Internal:

$\begin{array}{lll}\text { U. Balachandran } & \text { K. C. Goretta } & \text { J. J. Picciolo } \\ \text { I. D. Bloom } & \text { K. E. Gray } & \text { R. B. Poeppel (15) } \\ \text { S. Borys } & \text { D. Gruen } & \text { A. C. Raptis } \\ \text { M. B. Brodsky } & \text { M. Hash } & \text { J. L. Routbort } \\ \text { Y. S. Cha } & \text { J. R. Hull } & \text { W. J. Shack } \\ \text { G. Crabtree } & \text { J. Joigensen } & \text { T. P. Sheahen } \\ \text { S. E. Dorris } & \text { J. S. Kallend } & \text { J. P. Singh } \\ \text { E. Doss } & \text { R. T. Kampwirth } & \text { C. E. Till } \\ \text { H. Drucker } & \text { M. Kirk } & \text { L. R. Turner } \\ \text { B. Dunlap } & \text { D. S. Kupperman } & \text { A. Wagh } \\ \text { J. T. Dusek } & \text { S. Lake } & \text { R. W. Weeks } \\ \text { W. A. Ellingson } & \text { M. T. Lanagan } & \text { A. M. Wolsky } \\ \text { J. E. Emerson } & \text { C. A. Malefyt (2) } & \text { C. A. Youngdahl } \\ \text { F. Y. Fradin } & \text { V. A. Maroni } & \text { ANL Patent Dept. } \\ \text { B. R. T. Frost } & \text { R. L. McDaniel } & \text { ANL Contract File } \\ \text { R. Giese } & \text { D. J. Miller } & \text { TIS Files (3) }\end{array}$

\section{External:}

DOE-OSTI, for distribution per UC-201 (12)

ANL Libraries (2)

DOE Chicago Operations Office:

Manager

A. DasGupta

F. Herbaty

\section{U.S. Department of Energy. Washington:}

Office of Advanced Utility Concepts, Conservation and Renewable Energy:

J. Daley

R. Eaton III

Basic Energy Sciences-Materials Science, Energy Research:

I. L. Thomas

Materials and Components Technology Division Review Committee:

H. Berger, Industrial Quality, Inc., Gaithersburg, MD

M. S. Dresselhaus, Massachusetts Institute of Technology, Cambridge. MA

S. J. Green, Electric Power Research Institute, Palo Alto, CA

R. A. Greenkorn, Purdue University, West Lafayette, IN

C.-Y. Li, Cornell University, Ithaca, NY

P. G. Shewmon, Ohio State University, Columbus, OH

R. E. Smith, Electric Power Research Institute, NDE Ctr., Charlotte, NC 
Other - Industry - University

T. Bickel, Sandia National Laboratories

R. W. Boom, Applied Superconductivity Center. University of Wisconsin - Madison

R. Cass, HiTc Superconco, Inc.

D. L. Chung. State Untversity of New York - Buffalo

J. Clem, Ames Laboratory

R. Colwell, MagneTek Universal Electric

B. Currie. Pacific Northwest Laboratory

S. Danyluk, University of Illinois at Chicago

D. Divecha, Naval Surface Warfare Center

B. Dorothy, DuPont

D. K. Finnemore. Ames Laboratory

M. Fluss, Lawrence Livermore National Laboratory

S. Foner, Francis Bitter National Magnet Lab., Massachusetts Institute of Technology

J. R. Gaines, Superconductive Components, Inc.

C. Gallo, Superconix

M. Garbauskas, General Electric Company

D. Gubser, Naval Research Laboratory

R. A. Hawsey, Oak Ridge National Laboratory

H. Herro, Nalco Chemical Company

D. L. Johnson, Northwestern University

H. Jordan, Reliance Electric

J. B. Ketterson, Dept. of Physics and Astronomy, Northwestern University

J. L. Kirtley, Jr., Massachusetts Institute of Technology

M. Klein, University of Illinois at Urbana-Champaign

D. K. Kroeger, Oak Ridge National Laboratory

H. Kroger, Microelectronics and Computer Technology Corporation

D. C. Larbalestier, University of Wisconsin - Madison

R. A. Lemons, Los Alamos National Laboratory

M. Levy, Dept. of Physics, University of Wisconsin - Milwaukee

J. Lewis, University of Illinois at Urbana-Champaign

D. H. Liebenberg, Office of Naval Research

R. Loehman. Sandia National Laboratories

J. H. Long. Superconductor Technologies, Inc.

H. Madler, J. C. Petlau, Inc.

D. Madura, General Dynamics

A. Malozemoff, American Superconductor Corp.

C. Martin, SSC, Inc.

A. Marwick, IBM

T. Mason. Northwestern University

R. Mathisen, Foster-Miller, Inc.

B. McConnell, Solar Energy Research Institute

P. J. McGinn, University of Notre Dame

F. C. Moon, Cornell University

D. N. Palmer, ABB, Inc.

C. A. Parker, Allied Signal, Inc.

N. Phillips, Lawrence Berkeley Laboratory

R. Quinn, Los Alamos National Laboratory

R. Raman, Ceracon

R. F. Ranellone, Newport News Shipbullding

J. Rowell, Conductus

D. K. Sharma, Electric Power Research Institute 
S. Sinha. University of Illinols at Chicago

O. Smith, Illinois Superconductor Corp.

D. M. Smyth, Lehigh University

J. Stekly. Intermagnetics General Corp.

M. Suenaga, Materials Science Division. Brookhaven National Laboratory

R. Troendly, Shaped Wire, Inc.

B. Weinberger, United Technologies Research Center

D. O. Welch. Materials Science Division, Brookhaven National Laboratory

R. E. Williams, Ocean and Atmospheric Science, Inc.

J. Wu. Westinghouse Electric Corporation, Science and Technology Center

K. Youngdahl, Boeing Corporation

C. Zahopoulos, Northeastern Untversity 

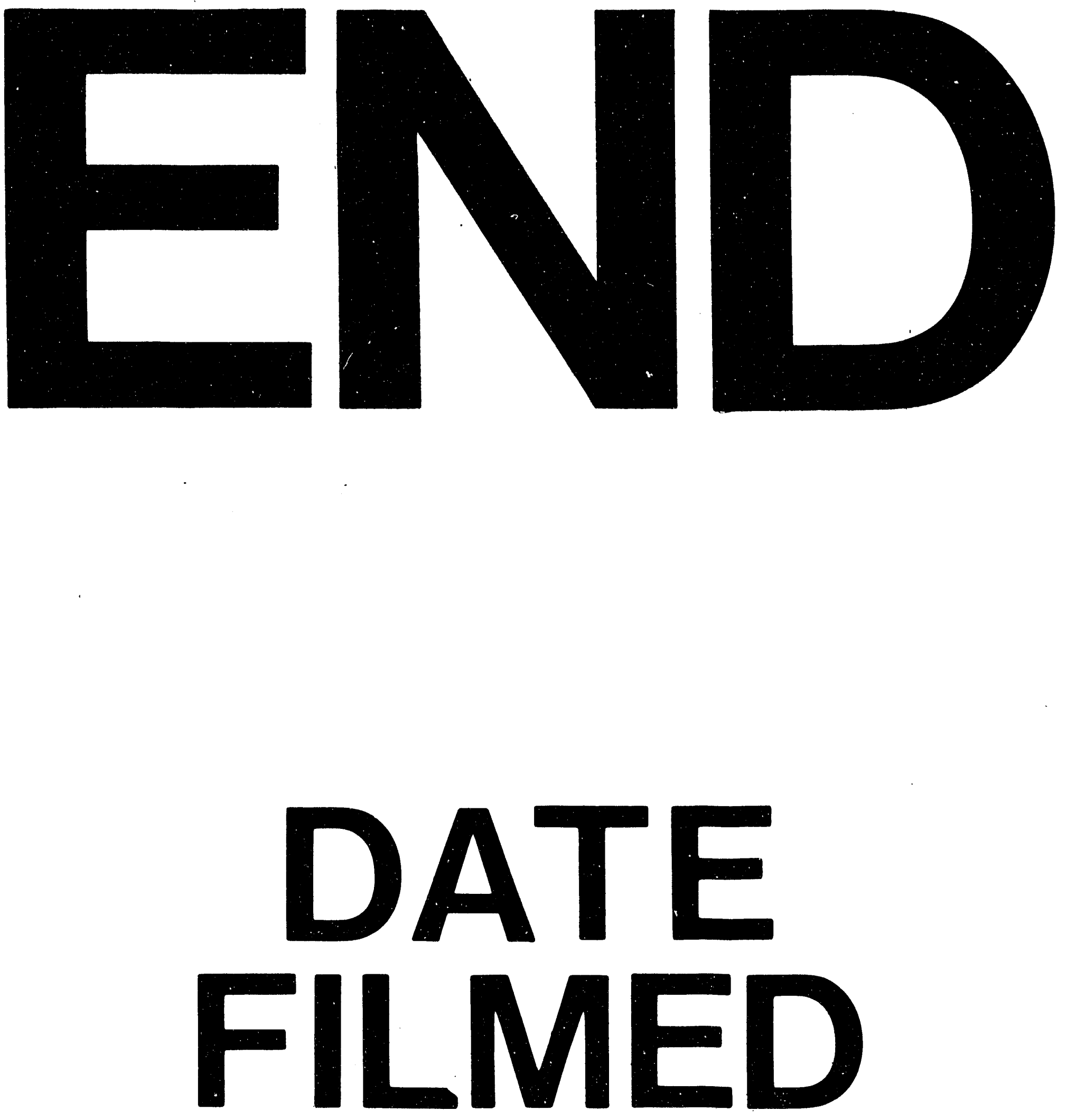

1

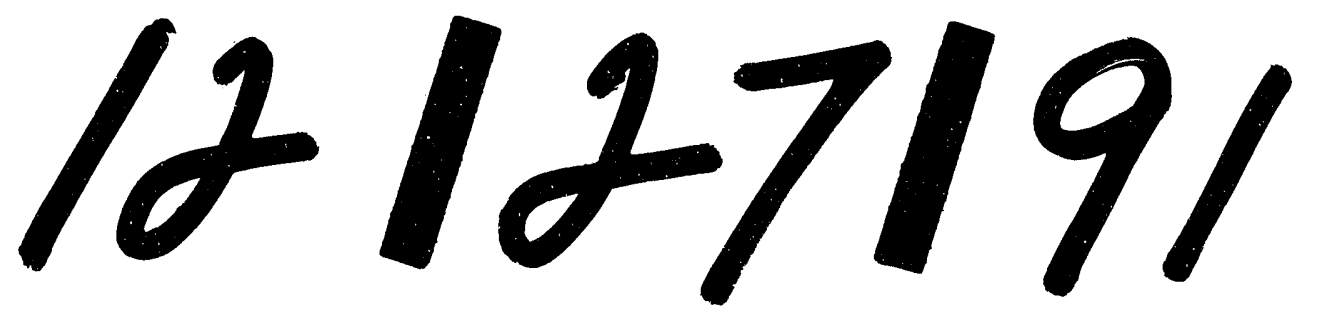

